\title{
CD52 inhibits Toll-like receptor activation of NF-kB and triggers apoptosis to suppress inflammation
}

\author{
Maryam Rashidi ${ }^{1,2}$, Esther Bandala-Sanchez ${ }^{1,2}$, Kate E Lawlor ${ }^{1,2}$, Yuxia Zhang ${ }^{1,2,4}$, Alana M Neale ${ }^{1,2}$, Swarna L Vijayaraj ${ }^{1,2}$, \\ Robert O'Donoghue ${ }^{1,2,5}$, John M Wentworth ${ }^{1,2}$, Timothy E Adams ${ }^{3}$, James E Vince ${ }^{\star, 1,2,6}$ and Leonard C Harrison ${ }^{\star, 1,2,6}$
}

Soluble CD52 is a small glycoprotein that suppresses T-cell activation, but its effect on innate immune cell function is unknown. Here we demonstrate that soluble CD52 inhibits Toll-like receptor and tumor necrosis factor receptor signaling to limit activation of $\mathrm{NF}-\kappa \mathrm{B}$ and thereby suppress the production of inflammatory cytokines by macrophages, monocytes and dendritic cells. At higher concentrations, soluble CD52 depletes the short-lived pro-survival protein MCL-1, contributing to activation of the BH3-only proteins BAX and BAK to cause intrinsic apoptotic cell death. In vivo, administration of soluble CD52 suppresses lipopolysaccharide (LPS)-induced cytokine secretion and other features of endotoxic shock, whereas genetic deletion of CD52 exacerbates LPS responses. Thus, soluble CD52 exhibits broad immune suppressive effects that signify its potential as an immunotherapeutic agent.

Cell Death and Differentiation (2018) 25, 392-405; doi:10.1038/cdd.2017.173; published online 15 December 2017

Evolutionarily conserved pattern recognition receptors (PRRs), such as Toll-like receptors (TLRs), detect microbial molecules termed pathogen-associated molecular patterns (PAMPs) to trigger innate immune responses against pathogens. ${ }^{1}$ These same PRRs can also respond to hostderived damage-associated molecular patterns (DAMPs), which helps coordinate the inflammatory responses involved in tissue regeneration and wound repair. Most PRRs, including TLR family members, induce inflammatory signaling through the activation of transcription factors, such as NF- $k B$, resulting in the production and secretion of pro-inflammatory cytokines and chemokines. ${ }^{2}$ Recent research has uncovered how PRR signaling contributes to a range of inflammation-driven disorders, from atherosclerosis and septic shock to autoimmune diseases and cancer. ${ }^{3}$ In this regard, agents that target innate immune PRR signaling pathways are limited and their discovery and development is considered a therapeutic priority. ${ }^{4,5}$

CD52 is a small glycosylphosphatidylinositol (GPI)anchored glycoprotein that was originally identified as the target of the lymphocyte-depleting CAMPATH rat monoclonal antibody. ${ }^{6,7}$ CD52 comprises a short peptide (12 amino acids in humans) that links its GPI anchor to a complex $N$-linked core fucosylated, polylactosamine multi-antennary sialylated glycan. ${ }^{8}$ CD52 is highly expressed on lymphoid cells, especially memory $C D 4^{+} \mathrm{T}$ cells and $\mathrm{B}$ cells, and on myeloid cells, particularly $\mathrm{CD}_{16}{ }^{+}$dendritic cells and monocytes. ${ }^{9}$ Despite the therapeutic use of CAMPATH to trigger complement-mediated lymphoid cell lysis in some malignancies and autoimmune diseases, the physiological roles of CD52 have not been clearly defined.

We previously found that CD4 ${ }^{+} \mathrm{T}$ cells with high levels of CD52 expression suppress bystander T-cell activation. ${ }^{10}$ The suppressive activity of CD52 $2^{\text {high }}$-expressing cells was due to soluble CD52, released by phospholipase C cleavage of the GPI-anchor. Soluble CD52 bound to the inhibitory sialic acidbinding immunoglobulin-like lectin (Siglec)-10 receptor, which is upregulated on activated T cells. Whether soluble CD52 has other functions, or can regulate other cell types, remains undetermined.

Here we demonstrate that soluble CD52 suppresses innate immune cell inflammatory cytokine production by limiting TLRinduced NF- $\kappa \mathrm{B}$ activation and, at high concentrations, induces apoptotic cell death. In vivo, administration of soluble CD52-Fc attenuated the inflammatory cytokine response and organ injury following injection of lipopolysaccharide (LPS). These findings thereby identify soluble CD52 as an anti-inflammatory molecule that acts broadly on innate immune cells to dampen TLR and TNF signaling responses.

\section{Results}

Soluble CD52 inhibits TLR-induced cytokine production. Soluble human and murine CD52 were generated as fusion proteins linked to the $\mathrm{Fc}$ fragment of IgG (CD52-Fc) and affinity-purified as previously described ${ }^{10}$ (Supplementary Figure S1A, see Materials and Methods). Fusion constructs contained a Factor Xa cleavage site between the CD52 extracellular and the Fc domains. To minimize Fc signaling, the

\footnotetext{
${ }^{1}$ The Walter \& Eliza Hall Institute of Medical Research, Parkville, Victoria 3052, Australia; ${ }^{2}$ Department of Medical Biology, The University of Melbourne, Parkville, Victoria 3010, Australia and ${ }^{3}$ CSIRO Manufacturing and Node of the National Biologics Facility, Parkville, Victoria 3052, Australia

*Corresponding author: JE Vince or LC Harrison, The Walter \& Eliza Hall Institute of Medical Research, 1G Royal Parade, Parkville, Victoria 3052, Australia. Tel: +61 39345 2555; Fax: +61 39347 0852; E-mail: vince@wehi.edu.au or harrison@wehi.edu.au

${ }^{4}$ Current address: Guangzhou Women and Children Medical Center, Guangzhou, China.

${ }^{5}$ Current address: Olivia Newton-John Cancer Research Institute, Heidelberg, Victoria 3084, Australia.

${ }^{6}$ These authors contributed equally to this work.

Received 09.3.17; revised 29.8.17; accepted 13.9.17; Edited by JA Cidlowski; published online 15.12.17
} 


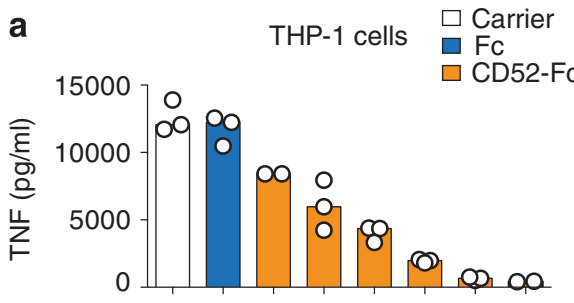

c

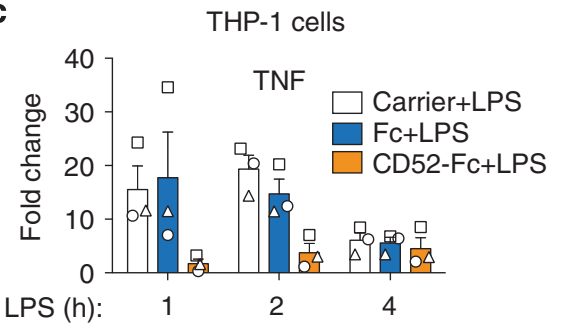

d THP-1 cells
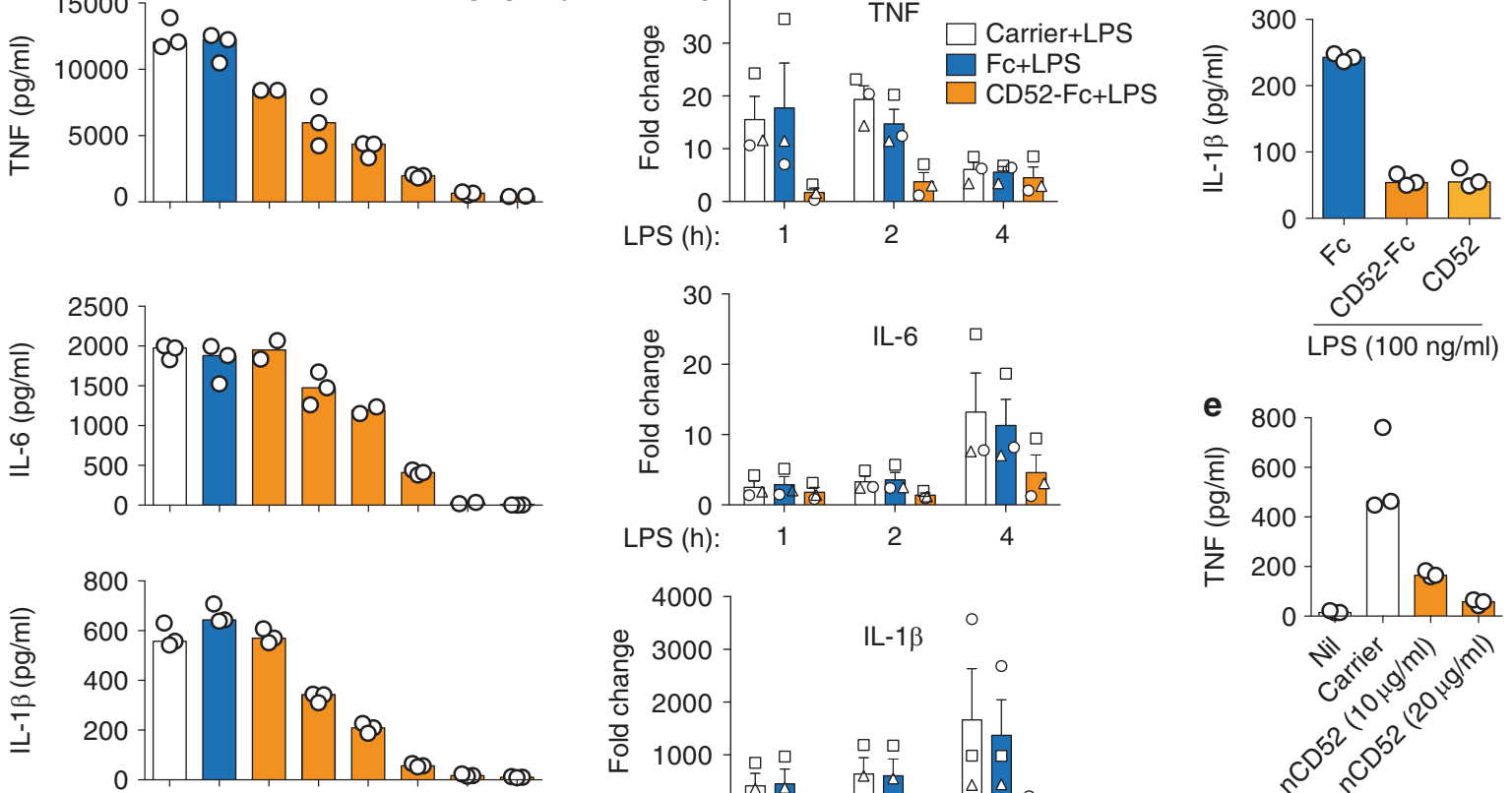

CD52/Fc $(\mu \mathrm{g} / \mathrm{ml}):$ Nil $\begin{array}{lllllll}50 & 0.5 & 5 & 10 & 20 & 30 & 40\end{array}$ LPS $(100 \mathrm{ng} / \mathrm{ml}):++++++++$
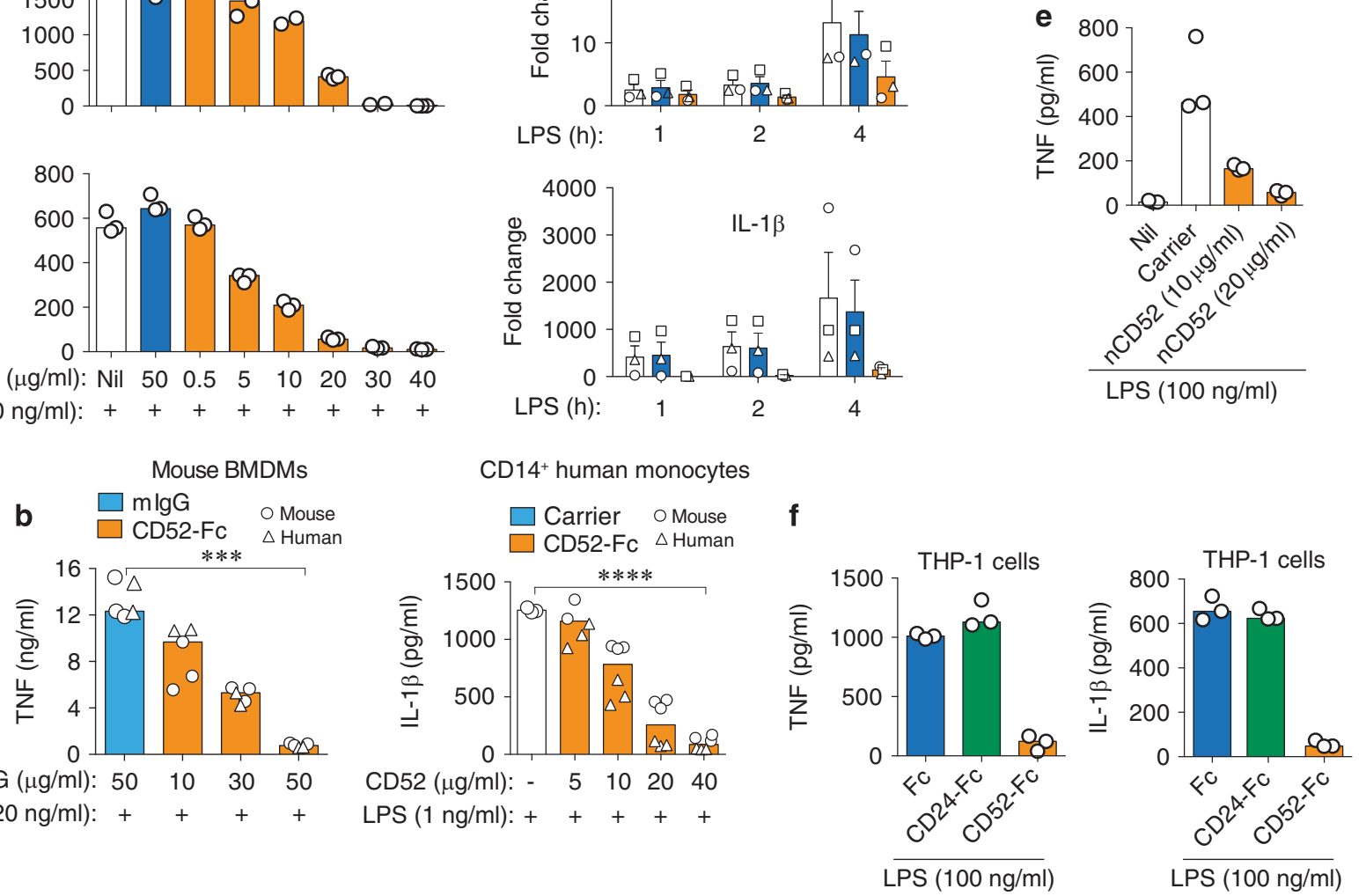

Figure 1 CD52-Fc suppresses LPS-stimulated cytokine production. (a) TNF, IL-6 and IL-1 $\beta$ in the medium of THP-1 cells incubated for $24 \mathrm{~h}$ with LPS (100 $\mathrm{ng} / \mathrm{ml}$ ) and either carrier (PBS), Fc control (50 $\mu \mathrm{g} / \mathrm{ml}$ ) or different concentrations of human CD52-Fc. (b) (left panel) TNF in the medium of BMDMs incubated for $6 \mathrm{~h}$ with LPS (20 ng/ml) and either control mlgG $(50 \mu \mathrm{g} / \mathrm{ml})$ or different concentrations of mouse (circle) or human (triangle) CD52-Fc; (right panel) IL-1 $\beta$ in the medium of CD14 ${ }^{+}$human monocytes incubated for $24 \mathrm{~h}$ with LPS (1 ng/ml) and different concentrations of either mouse (circle) or human (triangle) CD52-Fc. (c) Quantitative RT-PCR of TNF, IL-6 and IL-1 $\beta$ mRNA in THP-1 cells incubated with LPS (100 ng/ml) and either CD52-Fc or Fc for different times, relative to un-stimulated cells. (d) IL-1 $\beta$ in the medium of THP- 1 cells incubated for $5 \mathrm{~h}$ with LPS $(100 \mathrm{ng} / \mathrm{ml})$ and either Fc, CD52-Fc or CD52 from which Fc had been cleaved $(10 \mu \mathrm{g} / \mathrm{ml})$. (e) TNF in the medium of THP- 1 cells incubated for $5 \mathrm{~h}$ with LPS (100 ng/ml) and two concentrations of purified native CD52. (f) TNF and IL- $1 \beta$ in medium of THP-1 cells incubated for $24 \mathrm{~h}$ with LPS (100 ng/ml) and either Fc, hCD52-Fc or hCD24-Fc (20 $\mu \mathrm{g} / \mathrm{ml})$. Data are representative of three independent experiments. (a and $\mathbf{d}-\mathbf{f}$ ) medians of triplicates;(b) right: median of five mice, left: median of five replicates, pooled from two independent experiments; (c) mean \pm S.E.M. pooled from three independent experiments, each symbol representing one experiment. ${ }^{*} P<0.05,{ }^{* * *} P<0.001$. (b) KruskalWallis test

human IgG1 FC domain had been mutated to decrease its binding to $\mathrm{Fc}$ receptors ${ }^{11}$; the murine $\lg \mathrm{G} 2 \mathrm{c}$ Fc was derived from the NOD mouse strain.

To examine the effect of CD52-Fc on TLR signaling, human monocytic THP-1 cells were stimulated with LPS from Escherichia coli (O111:B4) in the presence of increasing CD52-Fc concentrations. CD52-Fc but not Fc caused a dosedependent inhibition of LPS-induced TNF, IL- 6 and IL-1 $\beta$ secretion (Figure 1a). Similarly, murine CD52-Fc inhibited LPS-stimulated TNF secretion from murine bone marrow-derived macrophages (BMDMs) (Figure 1b). Notably, both murine CD52-Fc and human CD52-Fc inhibited LPSinduced cytokine secretion by human monocytes or mouse macrophages (Figure 1b). Quantitative RT-PCR analysis of TNF, IL- 6 and IL-1 $\beta$ mRNA levels in THP-1 cells stimulated with LPS in the presence of CD52-Fc demonstrated that CD52-Fc acts to suppress LPS-induced cytokine production at the transcriptional level (Figure 1c).

To confirm that the Fc domain did not contribute to CD52-Fc signaling, we cleaved it from the fusion protein by treatment 
with Factor Xa (Supplementary Figure S1B). Importantly, CD52 lacking the Fc domain still retained the ability to inhibit LPS-induced cytokine secretion by THP-1 cells as efficiently as CD52-Fc (Figure 1d). Moreover, both native CD52 (nCD52) purified from human spleen cells, or medium containing soluble CD52 engineered to be constitutively secreted from HEK293T cells, also potently inhibited LPS-induced TNF secretion (Figure 1e and Supplementary Figure S2A). This phenomenon was not limited to LPS as CD52-Fc treatment also suppressed TNF production by THP-1 cells in response to a variety of TLR agonists including the DAMPs, HMGB1 and HSP90 (TLR2/4), and the PAMP, $\mathrm{Pam}_{3} \mathrm{CSK}_{4}$ (TLR1/2) (Supplementary Figures S2B and C).

To further confirm the specificity of CD52-Fc signaling we generated soluble recombinant CD24-Fc (Supplementary Figure S1A), as CD24 is another GPI-anchored glycoprotein whose genomic organization is similar to that of CD52. ${ }^{12}$ However, unlike CD52-Fc, CD24-Fc had no effect on LPSstimulated TNF or IL-1 $\beta$ secretion from THP-1 cells (Figure 1f).

Collectively, these findings demonstrate that soluble CD52 inhibits pro-inflammatory cytokine secretion in response to TLR signaling, and does so by blocking TLR-induced transcriptional activity.

Soluble CD52 inhibits TLR-induced NF- $K B$ and ERK signaling. To determine if treatment with CD52-Fc impacts TLR-induced activation of NF- $\kappa \mathrm{B}$, THP-1 cells were stably transduced with a lentiviral plasmid harboring a reporter gene carrying four canonical NF- $\kappa \mathrm{B}$ binding sites located immediately upstream of green fluorescent protein (GFP). As expected, when these cells were exposed to LPS to activate $\mathrm{NF}-\kappa \mathrm{B}$, we observed robust GFP expression. ${ }^{13}$ (Figure $2 \mathrm{a}$ ). Notably, the addition of CD52-Fc significantly suppressed $\mathrm{NF}-\kappa \mathrm{B}$ activation induced by LPS, $\mathrm{Pam}_{3} \mathrm{CSK}_{4}, \mathrm{HMGB1}$, HSP90, TNF or IL-1 $\beta$ treatment, in a dose- and timedependent manner (Figures $2 b-d$ ).

To examine where in the TLR signaling pathway CD52-Fc acts, BMDMs were treated with CD52-Fc for 15 min before exposure to LPS, and the time-dependent activation of TLR signaling components analyzed by immunoblot. Compared to carrier control, CD52-Fc limited LPS-induced NF- $\kappa$ B and ERK signaling as measured by a substantial delay in the phosphorylation of TAK1, IKKa/ $\beta, \mathrm{I}_{\kappa} \mathrm{B} a$ and $\mathrm{p} 65$, and also reduced p42/p44 ERK phosphorylation (Figure 2e). Of note, the ERK inhibitors U0126 and PD98059 ${ }^{14}$ limited LPSinduced TNF production in BMDMs despite NF- $\kappa \mathrm{B}$ activation being unaltered (Supplementary Figure S3), indicating that CD52-Fc is likely to inhibit TLR responses through the suppression of both NF-KB and ERK activity (Figure 2f).

\footnotetext{
At high concentrations, soluble CD52 induces apoptotic cell death. Activation of programmed cell death, such as apoptosis and necroptosis, can limit inflammatory signaling in vitro and in vivo. ${ }^{15,16}$ To determine if treatment with soluble CD52 induces cell death, THP-1 and mouse macrophage cell viability was assessed by Annexin $\mathrm{V}$ and propidium iodide (PI) staining, or by the release of cellular LDH into the medium. THP-1 cells treated with CD52-Fc but not Fc were killed in a dose- and time-dependent manner, and cell death occurred regardless of LPS treatment (Figures $3 a$ and $c$ and
}

Supplementary Figure S4A). CD52 from which Fc had been cleaved also induced killing of THP-1 cells (Supplementary Figure S4B). Importantly, however, CD52-FC mediated suppression of LPS-induced IL-1 $\beta$ was observed at lower concentrations of CD52-Fc $(10 \mu \mathrm{g} / \mathrm{ml})$ that did not cause appreciable cell death (Figures $3 a$ and $b$ ). These findings suggest that CD52-Fc inhibition of NF- $K$ B occurs independent of, or upstream of, the ability of CD52-Fc to induce cell death.

To explore the mechanism of CD52-Fc-induced cell death, THP-1 cells were first incubated with the broad-spectrum caspase inhibitor, QVD-OPh, to limit apoptotic cell death, or with the receptor-interacting protein kinase-1 (RIPK1) inhibitor, necrostatin-1 (Nec-1s), to block caspase-independent necroptotic cell death. Consistent with killing being due to caspase-dependent apoptosis, QVD-OPh, but not $\mathrm{Nec}-1 \mathrm{~s}$, attenuated CD52-Fc-induced cell death (Figure 3d).

Caspase-dependent apoptotic cell death occurs via the intrinsic (mitochondrial) or extrinsic (death receptor) pathways. Intrinsic apoptosis results from the permeabilization of mitochondrial membranes by BAX and BAK, resulting in cytosolic cytochrome c-mediated apoptosome formation and caspase- 9 activation. In contrast, extrinsic death receptor signaling results in the formation of a death-inducing signaling complex, in which caspase- 8 is processed and activated. Both caspase- 8 and caspase- 9 cleave and activate the same executioner caspases, such as caspase-3, which triggers the apoptotic phenotype. Notably, we observed that both caspase- 8 and caspase- 9 were processed to their active subunits in response to treatment with CD52-Fc, in a dose-dependent manner (Figure 3e). Moreover, BMDMs derived from Ripk ${ }^{-/} \mathrm{Casp}^{-/-}$mice (caspase-8 deletion alone is lethal) were significantly, but not completely, resistant to CD52-Fc-induced death when compared to cells derived from wild-type (WT) or necroptotic-deficient Ripk $3^{-/}$mice (Figure 3f). Neutralizing antibodies against TNF, FasL and TRAIL, even in combination, did not inhibit CD52-Fcinduced death (Figure $3 \mathrm{~g}$ ), despite their ability to block cell death or NF- $K B$ activity induced by their specific ligands (Supplementary Figure S4C). Thus, caspase-8 partly contributes to killing by CD52-Fc, but is unlikely to be activated by death receptor signaling.

CD52-Fc depletes MCL-1 and induces BAX and BAK signaling to efficiently activate caspase-8. Because CD52-Fc did not appear to engage death receptor signaling to activate caspase-8, we considered the possibility that caspase- 8 was activated downstream of intrinsic BAX- and BAK-dependent apoptosis. Kinetic analysis revealed that caspase-8, the caspase-8 inhibitor CFLIP, caspase-9, caspase-3 and the caspase substrate PARP were all cleaved within 90-120 min post treatment of BMDMs with high-dose CD52-Fc (Figure 4a). This parallels the known effects of the protein synthesis inhibitor cycloheximide $(\mathrm{CHX})$ that depletes the short-lived pro-survival BCL2 family member myeloid cell leukemia-1 (MCL-1) to promote intrinsic BAX/BAK-dependent apoptosis ${ }^{17,18}$ (Figure 4b). Notably, prior to the detection of processed caspases we observed that exposure to CD52Fc for 30 min also resulted in significantly decreased MCL-1 levels (Figure 4a). In contrast, expression of the other prosurvival BCL2 family members, BCL-XL and BCL2, was not altered by high-dose CD52-Fc (Supplementary Figure S4D). 
a

$\bar{\alpha}$

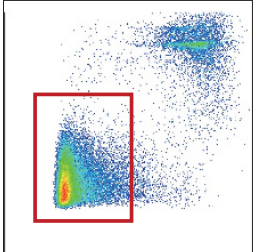

Annexin V

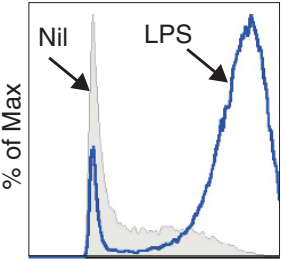

GFP

\section{C}

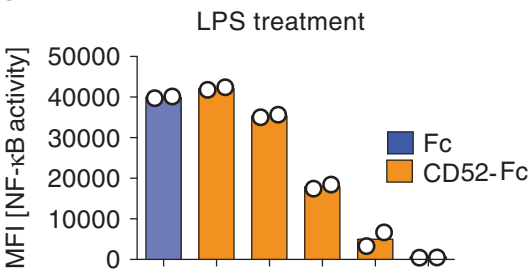

CD52/Fc $(\mu \mathrm{g} / \mathrm{ml}): \begin{array}{llllll}50 & 5 & 10 & 20 & 30 & 40\end{array}$
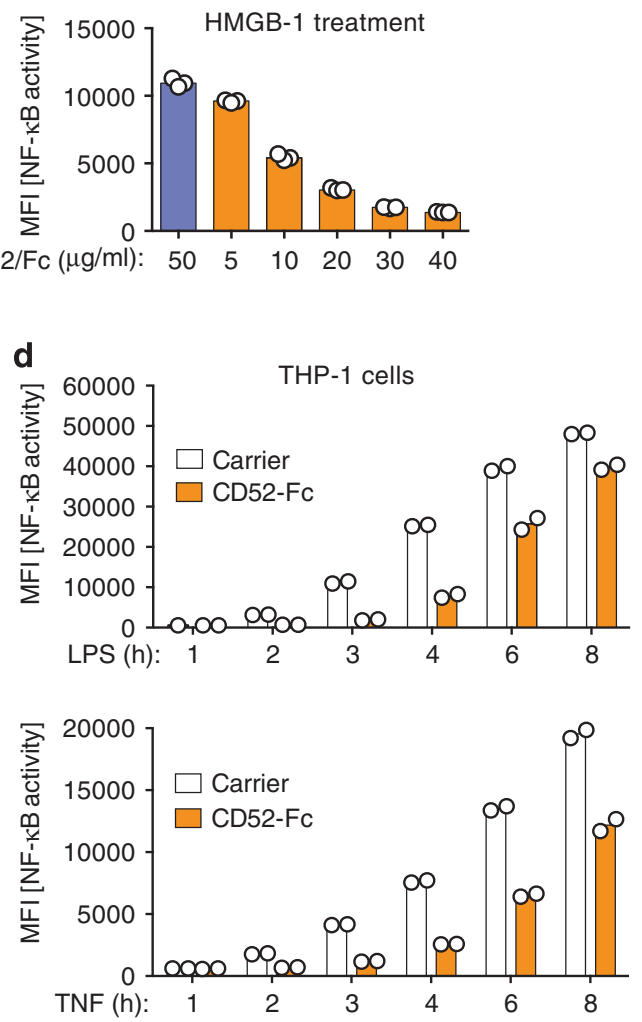

\section{b}

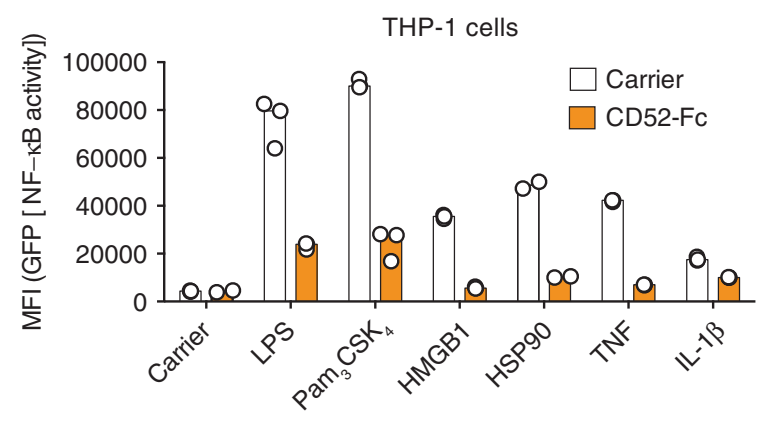

e

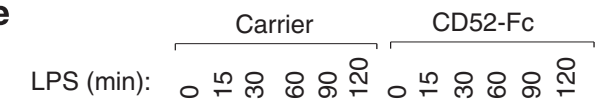

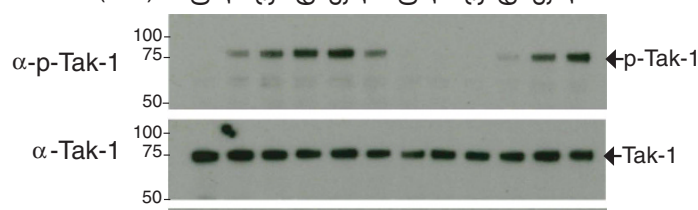

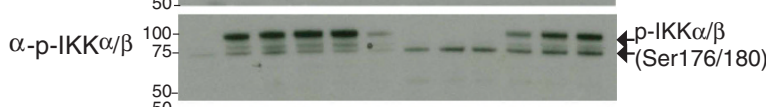

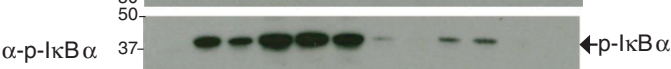

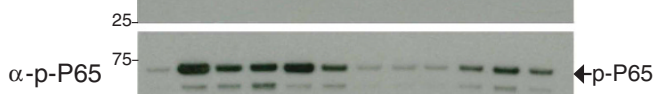
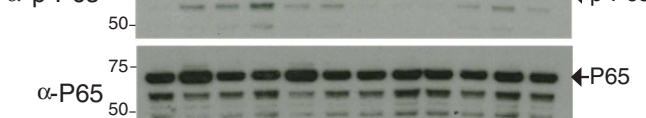

$\alpha-\mid \kappa B \alpha$
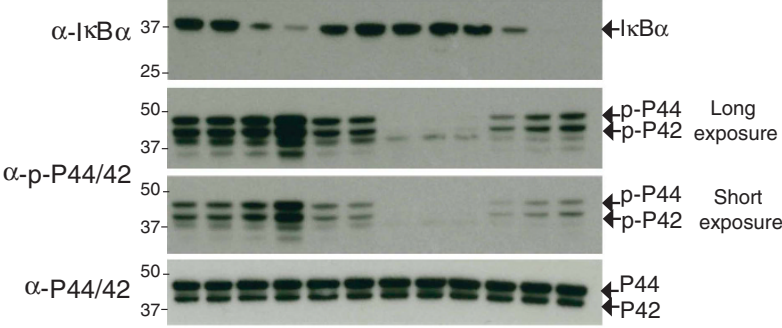

Ponceau S

f

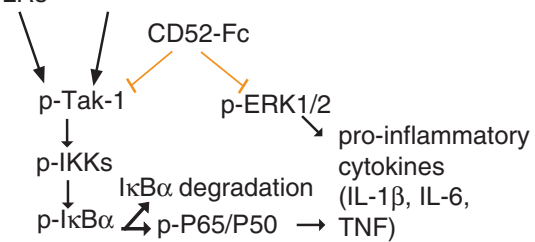

Figure 2 CD52-Fc inhibits TLR-induced NF- $k B$ and ERK activation. (a) Flow cytometric analysis of GFP expression (readout of NF- $k B$ activation) in reporter THP-1 cells in the absence (gray-shaded curve) or presence of LPS $(1 \mu \mathrm{g} / \mathrm{ml})$ (blue curve) after $3 \mathrm{~h}$ of treatment. Annexin V-and PI-positive cells were excluded from the analysis. (b) Mean fluorescence intensity (MFI) of NF- $k B$ GFP reporter THP-1 cells incubated for $5 \mathrm{~h}$ with LPS (100 ng/ml), Pam ${ }_{3} \mathrm{CSK}_{4}(100 \mathrm{ng} / \mathrm{ml}), \mathrm{HMGB} 1$ (10 $\left.\mu \mathrm{g} / \mathrm{ml}\right), \mathrm{HSP} 90$ (10 $\left.\mu \mathrm{g} / \mathrm{ml}\right), \mathrm{rhTNF}$ $(20 \mathrm{ng} / \mathrm{ml})$ or rhlL-1 $\beta(20 \mathrm{ng} / \mathrm{ml})$ and either carrier (PBS) or CD52-Fc (30 $\mu \mathrm{g} / \mathrm{ml})$. (c) MFI of GFP expression in NF- $k$ B reporter THP-1 cells incubated for $5 \mathrm{~h}$ with LPS $(1 \mu \mathrm{g} / \mathrm{ml})$ (top) or HMGB1 $(10 \mu \mathrm{g} / \mathrm{ml}$ ) (bottom) and either Fc control (50 $\mu \mathrm{g} / \mathrm{ml})$ or various concentrations of CD52-Fc (d) MFl of GFP expression in NF- $k B$ reporter THP-1 cells incubated for different time points with LPS $(1 \mu \mathrm{g} / \mathrm{ml})$ or rhTNF ( $20 \mathrm{ng} / \mathrm{ml}$ ) with either carrier (PBS) or CD52-Fc ( $30 \mu \mathrm{g} / \mathrm{ml})$. (e) BMDMs were incubated for up to $120 \mathrm{~min}$ with LPS (20 $\mathrm{ng} / \mathrm{ml})$ in the presence of carrier (PBS) or CD52-Fc (40 $\mu \mathrm{g} / \mathrm{ml})$ (added $15 \mathrm{~min}$ prior to LPS) and total cell lysates analyzed by immunoblot, as indicated. (f) Schematic model for how CD52Fc suppresses inflammatory cytokine production and secretion. Ponceau stain serves as loading control. Data are representative of two independent experiments 
a

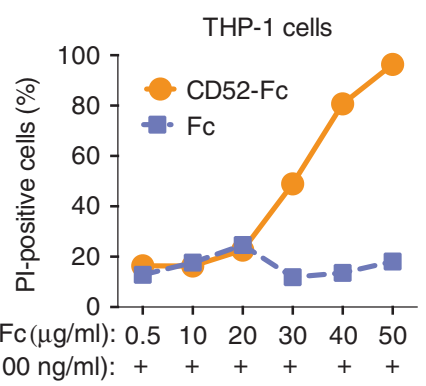

b

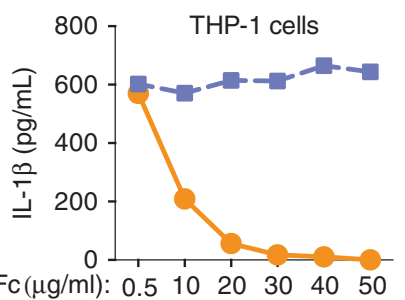

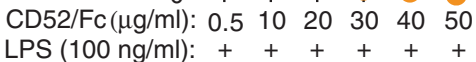

c

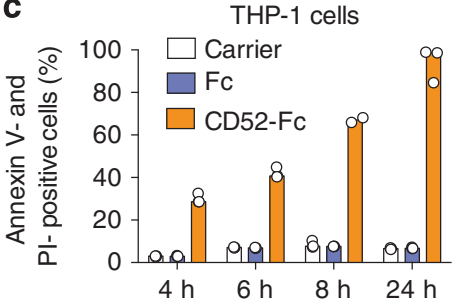

d

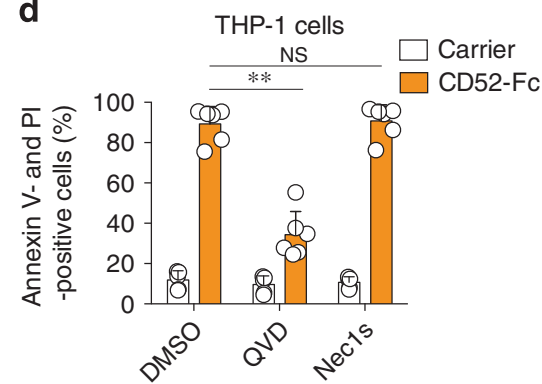

f

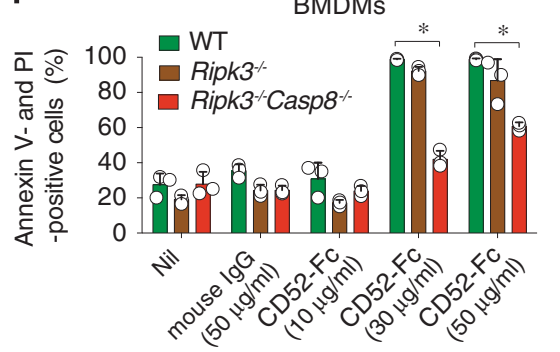

g

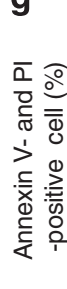

e

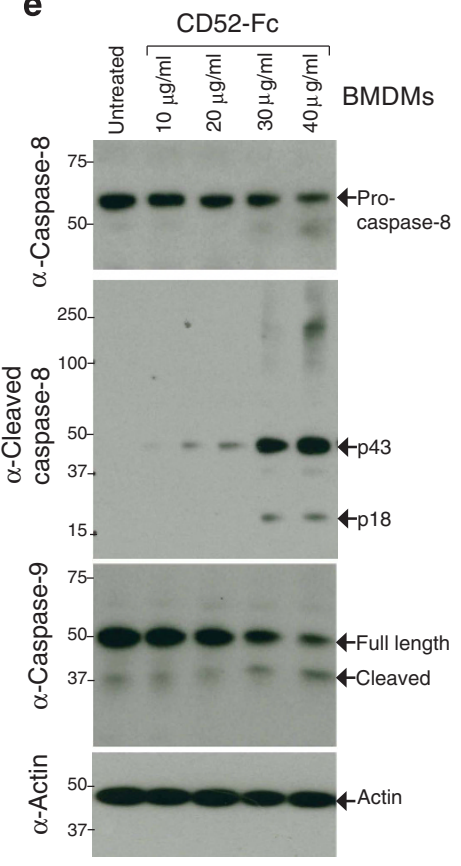

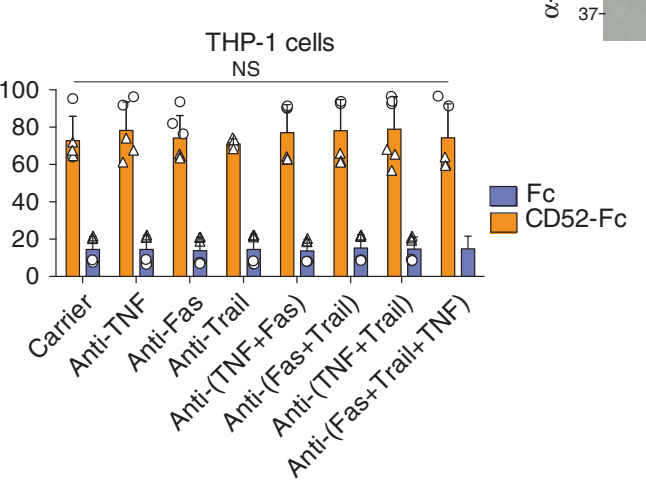

Figure 3 High concentrations of CD52-Fc induce apoptotic cell death. (a) PI-positive cells and (b) IL-1 $\beta$ concentrations in the medium of THP-1 incubated for $24 \mathrm{~h}$ with LPS $(100 \mathrm{ng} / \mathrm{ml})$ and the indicated concentrations of CD52-Fc or Fc control. (c) Annexin V-and PI-positive THP-1 cells after incubation with either carrier (PBS), CD52-Fc or Fc (50 $\mu \mathrm{g} /$ $\mathrm{ml}$ ) for the indicated times. (d) Annexin V- and PI-positive THP-1 cells after incubation for $16 \mathrm{~h}$ with either carrier (PBS) or CD52-Fc (50 $\mu \mathrm{g} / \mathrm{ml})$, and pre-incubation ( $3 \mathrm{~h}$ ) with carrier (DMSO), QVD-OPh $(50 \mu \mathrm{M})$ or necrostatin $1 \mathrm{~s}(\mathrm{Nec} 1 \mathrm{~s})(50 \mu \mathrm{M})$. (e) WT murine BMDMs were incubated for $6 \mathrm{~h}$ with the indicated concentrations of CD52-Fc and

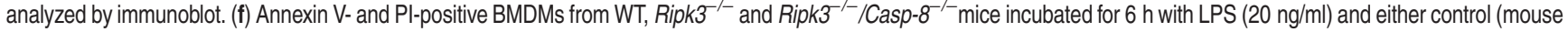
$\mathrm{lgG}, 50 \mu \mathrm{g} / \mathrm{ml})$ or the indicated concentrations of CD52-Fc (10,30, $50 \mu \mathrm{g} / \mathrm{ml})$. (g) Annexin V-and Pl-positive THP-1 cells after incubation for $18 \mathrm{~h}$ with either Fc or hCD52-Fc $(50 \mu \mathrm{g} / \mathrm{ml})$, and pre-incubation with carrier (PBS), anti-TNF, anti-Trail or anti-Fas blocking antibodies (20 $\mu \mathrm{g} / \mathrm{ml}, 30 \mathrm{~min})$. Data are representative of two independent experiments; (c) medians of triplicates; (d) mean \pm S.D. of 5-6 replicates pooled from two independent experiments; (f) $n=3$ mice per group; (g) mean \pm S.D. of five replicates pooled from two independent experiments. ${ }^{*} P<0.05,{ }^{* *} P<0.01,{ }^{* *} P<0.001$. (d,f) Mann-Whitney test, $(\mathbf{g})$ Kruskal-Wallis test

The significant depletion of MCL-1 following treatment with CD52-Fc suggested that CD52-Fc might induce intrinsic apoptosis by activating $\mathrm{BAX}$ and BAK. Consistent with this idea, $\mathrm{Bax}^{-1-} \mathrm{Bak}^{-/-}$BMDMs treated with CD52-Fc, or the intrinsic apoptotic stimulus $\mathrm{CHX}$, exhibited substantially decreased CD52-Fc-induced processing of caspase-9 and PARP when compared to WT BMDMs (Figure 4b). BAX and BAK deletion also decreased CD52-Fc-induced caspase-8 processing, indicating that caspase- 8 activation likely results from effector caspase activity that occurs downstream of BAX/ BAK and apoptosome formation. ${ }^{19,20}$ Importantly, treatment with CD52-Fc resulted in an equivalent decrease in MCL-1 in $\mathrm{Bax}^{-/-} \mathrm{Bak}^{-/}$and WT cells, placing CD52-FC-induced loss of MCL-1 upstream of BAX and BAK activation (Figure $4 \mathrm{~b}$ ). In agreement with the immunoblot data, both CD52-FC- and
$\mathrm{CHX}$-induced death was significantly less in $\mathrm{Bax}^{-/-} \mathrm{Bak}^{-/-}$ BMDMs relative to WT cells, as measured by Annexin V and PI uptake (Figure 4c). Therefore, treatment with high-dose CD52Fc depletes MCL-1. This is likely to be important for triggering BAX/BAK and downstream caspase- 9 and caspase- 8 activation, the later being enhanced by decreased $C F L I P_{L}$ levels, to induce apoptotic cell death.

Activation of NF- $K B$ results in the transcription of antiapoptotic genes, such as the caspase-8 inhibitor cFLIP and MCL-1, ${ }^{21,22}$ both of which are depleted by treatment with CD52-Fc (Figure 4a). Therefore, to test if NF- $k \mathrm{~B}$ activation might confer resistance to CD52-Fc killing, we introduced a 4hydroxy tamoxifen (4HT)-inducible ${ }^{23}$ constitutively active IKK construct (IKK2 S177E, S181E; IKK2-EE) into NF-KB reporter THP-1 cells. ${ }^{24}$ As expected, the induction of IKK2-EE with $4 \mathrm{HT}$ 
a

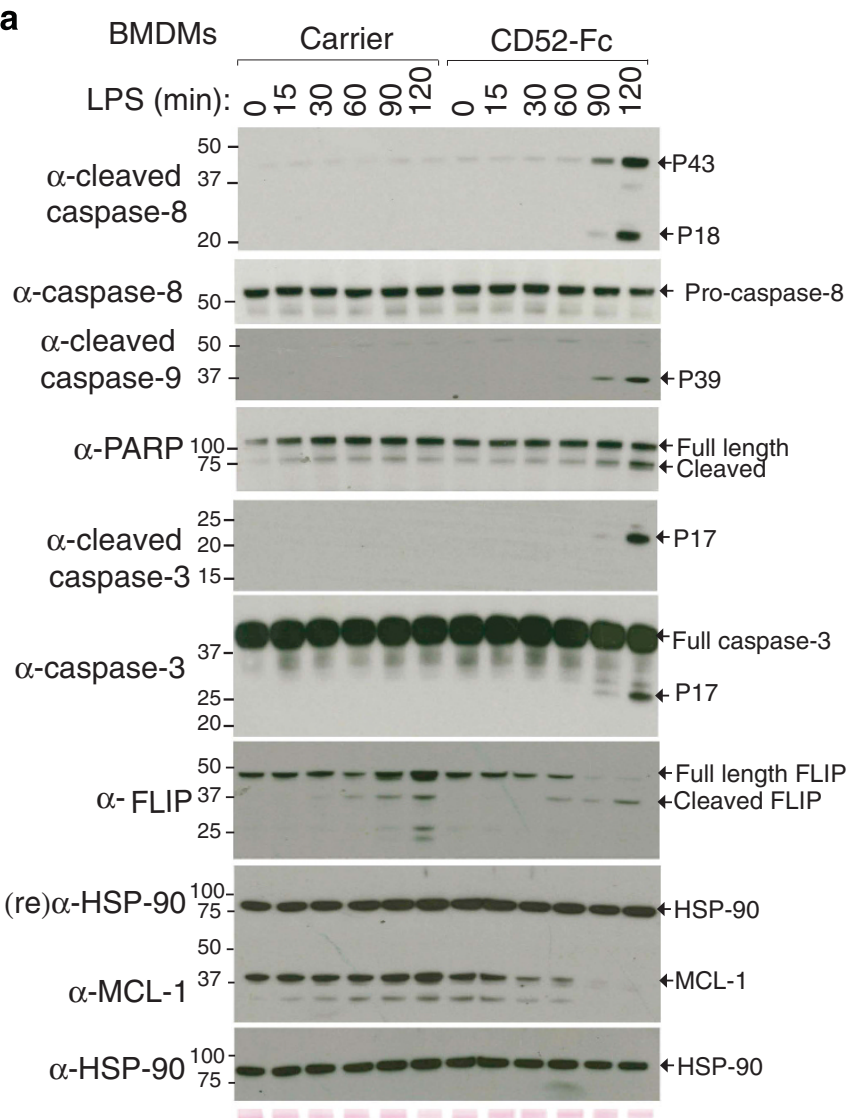

Ponceau S b

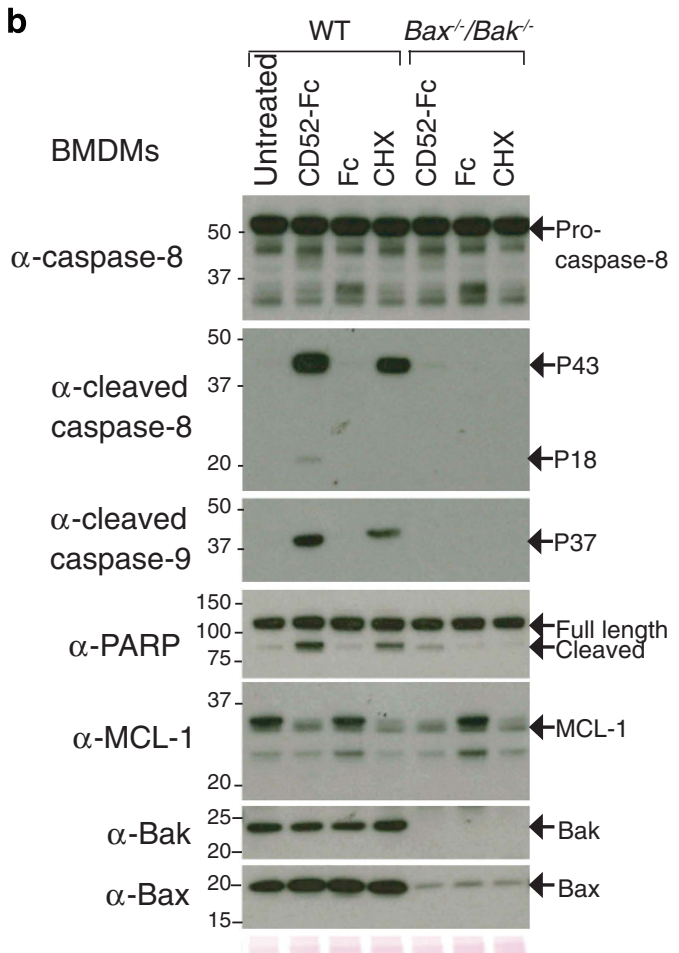

Ponceau S

C

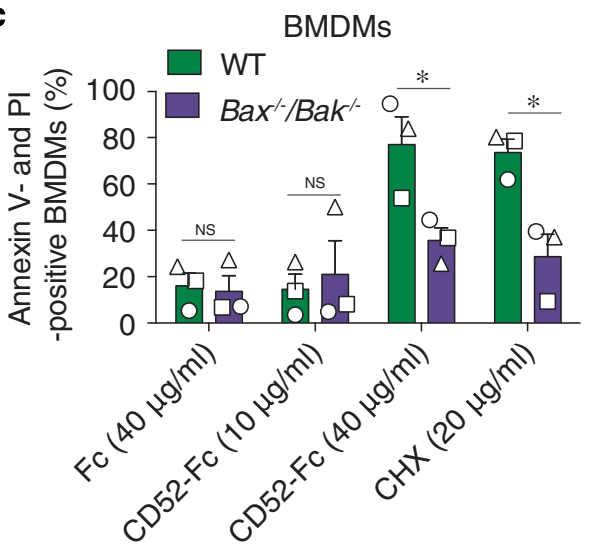

Figure 4 CD52-Fc induces apoptotic cell death through BAX/BAK activation. (a) BMDMs were incubated for different times with LPS (20 ng/ml) and either carrier (PBS) or CD52-Fc (40 $\mu \mathrm{g} / \mathrm{ml})$ as indicated and analyzed by immunoblot. (b) BMDMs from the indicated genotypes were incubated for $2 \mathrm{~h}$ with either Fc control, CD52-Fc (40 $\mu \mathrm{g} / \mathrm{ml})$ or cycloheximide (CHX; $20 \mu \mathrm{g} / \mathrm{ml})$ and analyzed by immunoblot. (c) Annexin V- and PI-positive BMDMs from WTand $\mathrm{Bax}^{-1-} / \mathrm{Bak}^{-/-}$mice after incubation of cells for $16 \mathrm{~h}$ with either Fc $(40 \mu \mathrm{g} / \mathrm{ml})$, CD52-Fc $(10,40 \mu \mathrm{g} / \mathrm{ml})$ or $\mathrm{CHX}(20 \mu \mathrm{g} / \mathrm{ml})$. (c) $n=3$ mice pooled from three independent experiments. ${ }^{*} P<0.05$; Mann-Whitney test

resulted in robust NF-kB activity (Figure 5a), which was sufficient to decrease cell death (Figure $5 b$ ) and caspase cleavage (Figure 5c) induced by CD52-Fc. Importantly, this decrease in CD52-Fc-induced cell death correlated with increased expression of MCL-1 and cFLIP (Figure 5c). Consistent with these observations, 4HT-inducible expression of MCL-1 significantly decreased caspase cleavage and cell death due to CD52-Fc treatment (Figures $5 \mathrm{~d}$ and e). In contrast, overexpression of $C F L I P L$ alone resulted in caspase processing and cell death, which was increased by CD52-Fc treatment (Figure 5e). This finding agrees with evidence that high nonphysiological overexpression of $c-F L I P_{L}$ can be cytotoxic by itself, ${ }^{25}$ probably by promoting DED-mediated procaspase- 8 oligomer assembly to initiate caspase-8 activation. ${ }^{26}$

Collectively, these results indicate that CD52-Fc inhibition of NF- $\kappa B$ activity and decreased expression of pro-survival genes is likely to contribute to CD52-Fc-induced apoptosis (Figure 5f). 


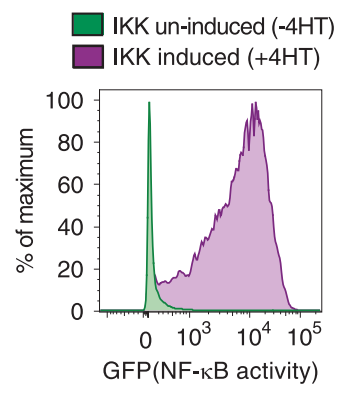

\section{b}

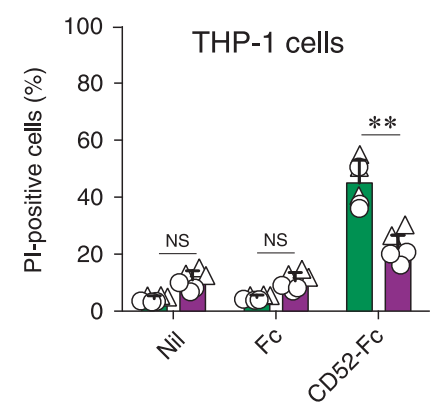

d

$\mathrm{CFLIP}_{\mathrm{L}}$ (induced) ++--++------

MCL-1 (induced) $++----\cdots++--$

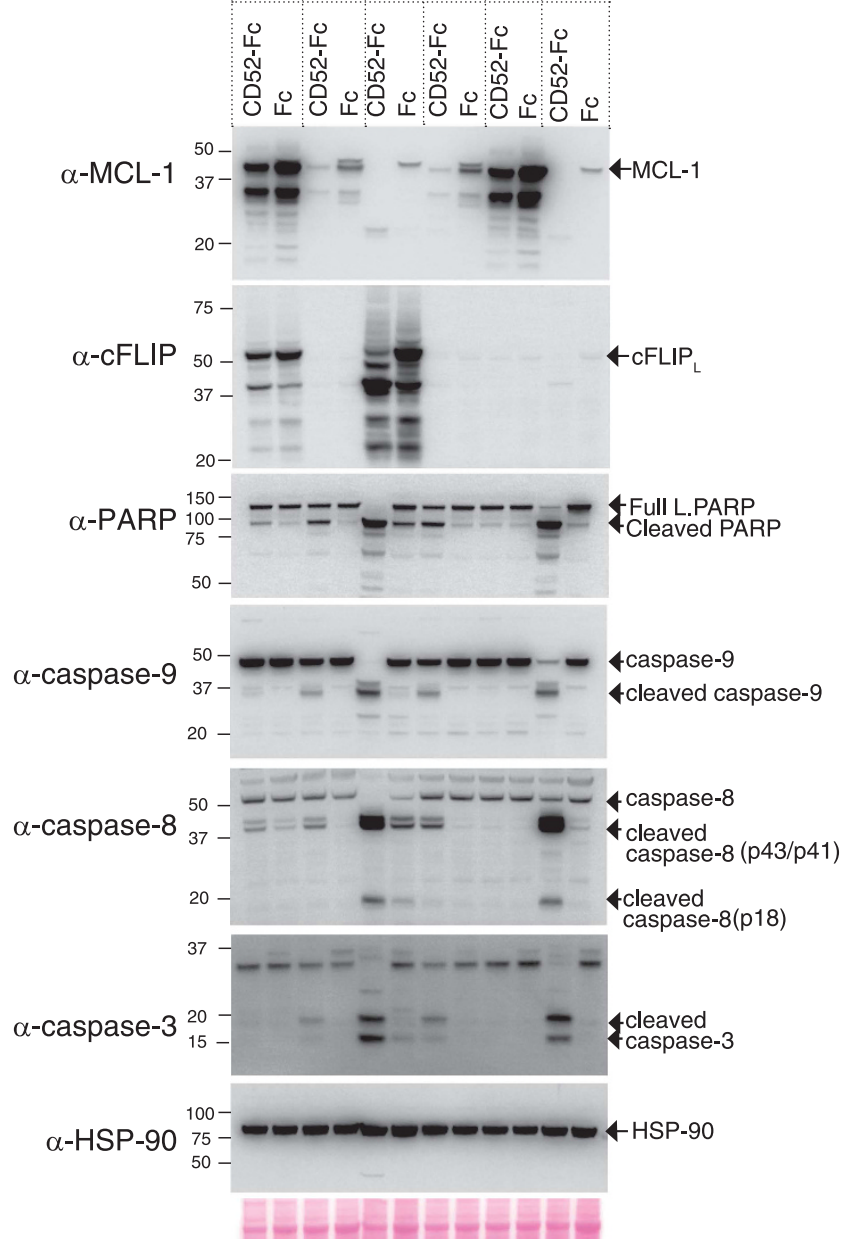

C

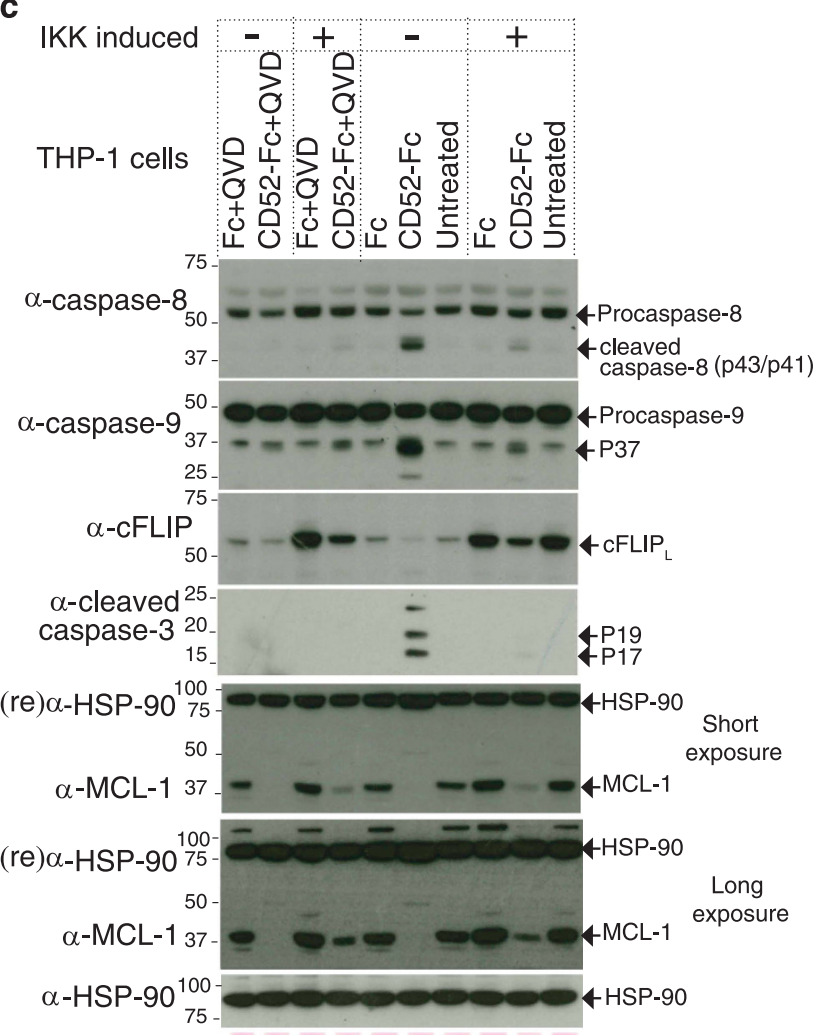

Ponceau S
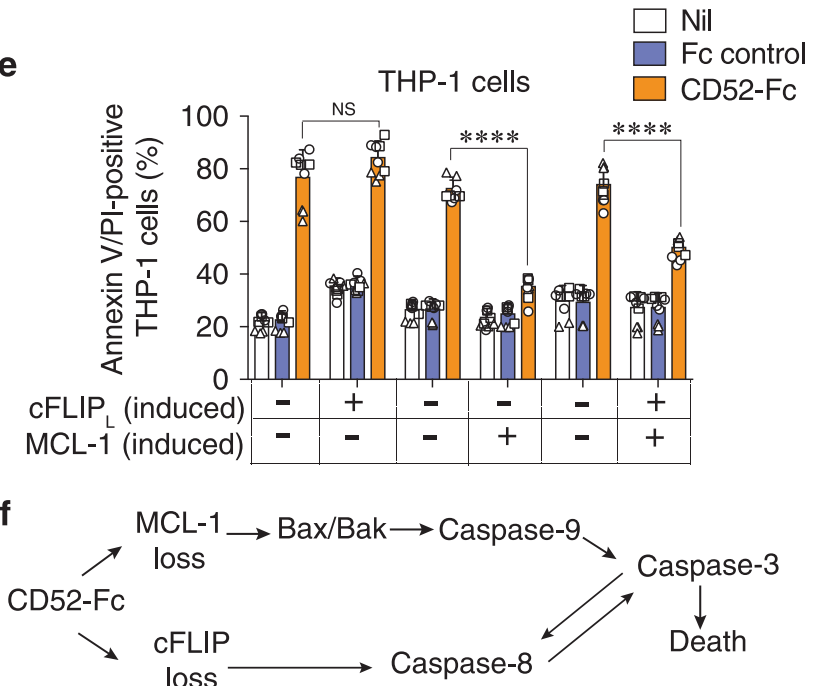

Ponceau S

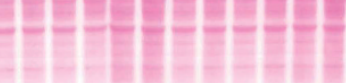

Figure 5 CD52-Fc triggers MCL-1 and cFLIP depletion to promote apoptotic cell death. (a) NF- $\kappa B$ GFP expression in THP-1 cells analyzed $16 \mathrm{~h}$ after 4-hydroxytamoxifen (10 nM 4HT; purple area) treatment to induce expression of constitutively active (EE) IKK2. (b) Pl uptake by THP-1 cells was analyzed by flow cytometry after incubation for $8 \mathrm{~h}$ with nothing (Nil), control Fc or CD52-Fc $(40 \mu \mathrm{g} / \mathrm{ml})$, with or without pre-incubation with $4 \mathrm{HT}(10 \mathrm{nM}, 16 \mathrm{~h})$ to induce constitutively active (EE) IKK2 expression. (c) THP-1 cell lysates analyzed by immunoblot after $8 \mathrm{~h}$ treatment with either $\mathrm{Fc}$ or CD52-Fc $(40 \mu \mathrm{g} / \mathrm{ml})$, with or without pre-incubation with $4 \mathrm{HT}(10 \mathrm{nM}, 16 \mathrm{~h})$ to induce constitutively active (EE) IKK2 expression \pm QVD-OPh ( $50 \mu \mathrm{M}, 1 \mathrm{~h}$ pre-treatment). (d) THP-1 cell lysates were analyzed by immunoblot after $2 \mathrm{~h}$ treatment with either $\mathrm{Fc}$ or CD52-Fc ( $50 \mu \mathrm{g} / \mathrm{ml})$, with or without preincubation with 4HT (10 nM; induces expression of MCL-1), doxycycline (Dox) $(1 \mu \mathrm{g} / \mathrm{ml}$; induces expression of CFLIP $)$ or both $4 \mathrm{HT}$ and Dox for $16 \mathrm{~h}$. (e) Annexin V-and PI-positive THP-1 cells was analyzed by flow cytometry after incubation for $8 \mathrm{~h}$ with control $\mathrm{Fc}$ or CD52-Fc (50 $\mu \mathrm{g} / \mathrm{ml})$, with or without pre-incubation with $4 \mathrm{HT}$ (10 nM; MCL-1 expression), Dox $(1 \mu \mathrm{g} / \mathrm{ml} \mathrm{cFLIPL}$ expression) or both 4HTand Dox. (f) Schematic model for how CD52-Fc induces apoptosis through MCL-1 and cFLIP loss. (b) mean \pm S.D. of 5-6 replicates pooled from two independent experiments, (e) mean \pm S.D. of 8-9 replicates pooled from three independent experiments. ${ }^{* *} P<0.01,{ }^{* * \star} P<0.0001 ;(\mathbf{b}, \mathbf{e})$ Mann-Whitney test 
a BMDMs

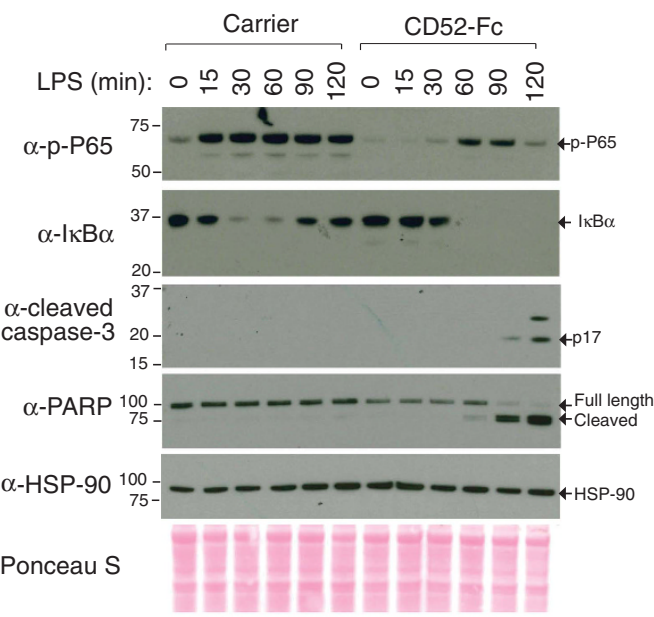

b

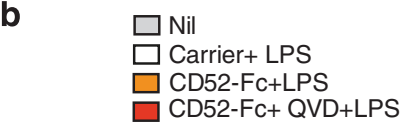

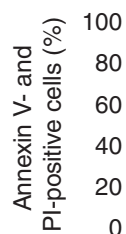

-

(h): 2

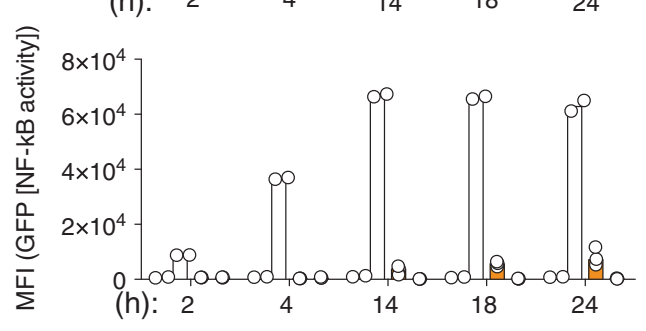

C

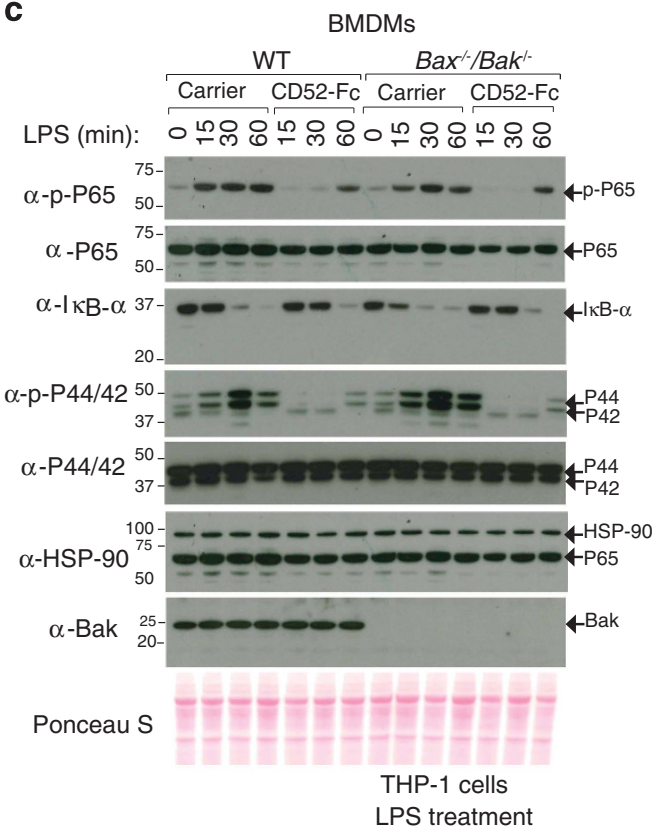

d

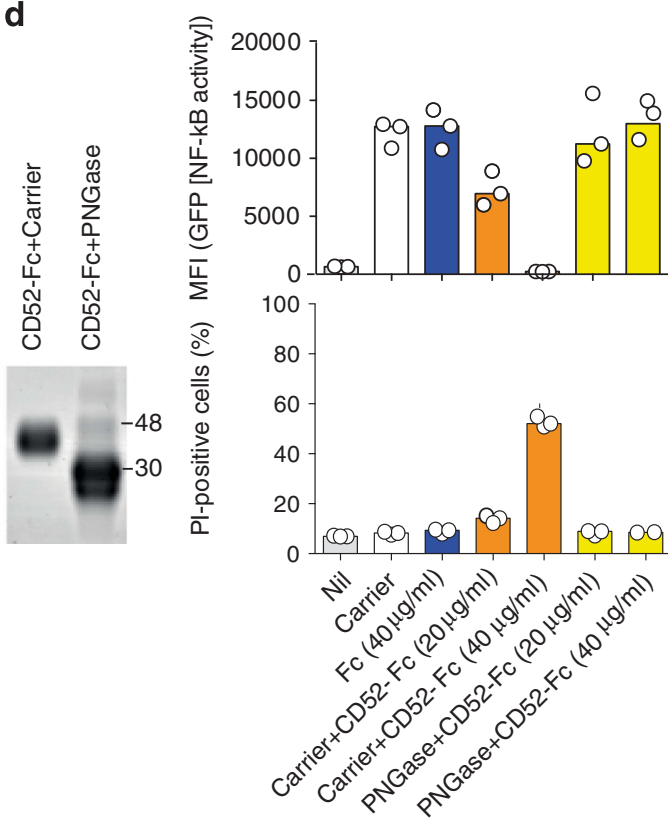

Figure 6 CD52-Fc inhibition of NF- $\kappa$ B can be separated from CD52-Fc-induced cell death. (a) Immunoblot analysis of BMDM total cell lysates following treatment with LPS $(20 \mathrm{ng} / \mathrm{ml}$ ) and either carrier (PBS) or CD52-Fc (40 $\mu \mathrm{g} / \mathrm{ml}$ ) (added 15 min prior to LPS). (b) Annexin V- and PI-positive (top panel) and mean fluorescence intensity (MFI) of NF- $k \mathrm{~B}$ GFP reporter cells (bottom panel) following treatment with LPS $(1 \mu \mathrm{g} / \mathrm{ml}$ ) and either carrier (PBS) or CD52-Fc $(50 \mu \mathrm{g} / \mathrm{ml})$, with or without pre-incubation with QVD-OPh (50 $\mu \mathrm{M}$, $1 \mathrm{~h})$. (c) Immunoblot analysis BMDMs incubated with LPS (20 ng/ml) and either carrier (PBS) or CD52-Fc (40 $\mu \mathrm{g} / \mathrm{ml}, 15 \mathrm{~min})$. (d) SDS-PAGE and Coomassie blue staining of CD52-Fc incubated with PNGase F or carrier (PNGase F reaction buffer) overnight (left inset). Flow cytometric analysis of NF- $\kappa \mathrm{B}$ activation (top panel) and PI uptake (bottom panel) in NF- $k$ B GFP reporter THP-1 cells after incubation of cells for $5 \mathrm{~h}$ with LPS (100 ng/ml), carrier (PBS), Fc or CD52-Fc treated with PNGase F or carrier (right inset). Data are representative of 2-3 independent experiments. $(\mathbf{b}, \mathbf{d})$ median of 2-3 replicates

CD52-Fc inhibits NF- $\mathrm{B}$ to limit TLR-induced cytokine production before inducing cell death. Our results show that CD52-Fc inhibits TLR-induced NF- $K B$ and cytokine production, and also induces apoptotic cell death. We therefore investigated whether apoptotic signaling might contribute to CD52-Fc suppression of TLR signaling. We observed, however, that inhibition of LPS-induced cytokine secretion by CD52-Fc occurred prior to detectable cell death (Figures $3 a$ and b). In fact, low-dose CD52-Fc inhibited LPSinduced NF- $K \mathrm{~B}$ activation within $15 \mathrm{~min}$, well before the detection of caspase-3 and PARP cleavage (Figure 6a). Moreover, inhibition of CD52-Fc-induced killing by treatment with the pan-caspase inhibitor QVD-OPh, deletion of BAX and BAK, or removal of caspase-8, did not alter the ability of 
$\square$ LPS+Control OPBS $\square$ LPS+CD52-Fc $\stackrel{\text { mCD52-Fc }}{\triangle}$

b

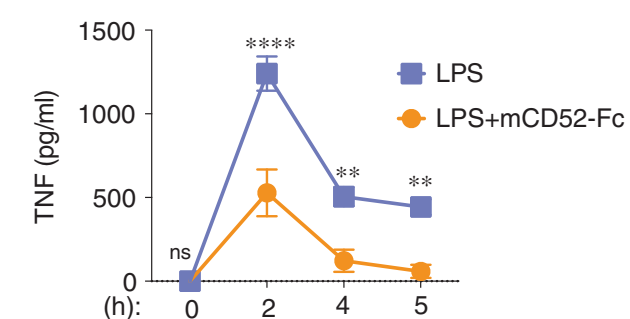

C

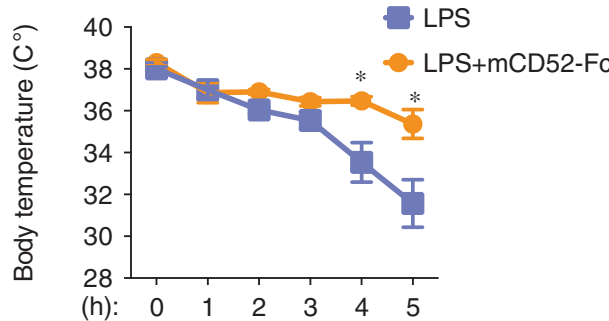

d

\begin{tabular}{|l|c|c|c|}
\hline & $\begin{array}{c}\text { Reduced } \\
\text { mobility }\end{array}$ & Ruffled fur & Diarrhoea \\
\hline LPS & $++++/+++++$ & $++/+++$ & $++/+++$ \\
\hline $\begin{array}{l}\text { LPS }+ \\
\text { CD52-FC }\end{array}$ & $+/-$ & $+/-$ & $+/-$ \\
\hline
\end{tabular}

e

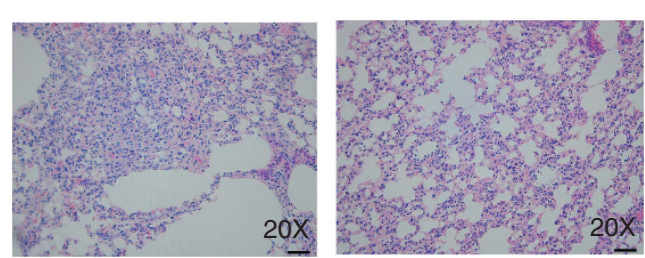

LPS (alveolitis grade 6) LPS+CD52-Fc (alveolitis grade 2)

\begin{tabular}{|l|c|c|c|}
\hline & Bronchial & Vascular & Alveolar \\
\hline LPS & $+/+$ & + & $+++/++++++$ \\
\hline $\begin{array}{l}\text { LPS+ } \\
\text { CD52-FC }\end{array}$ & + & - & +++ \\
\hline
\end{tabular}
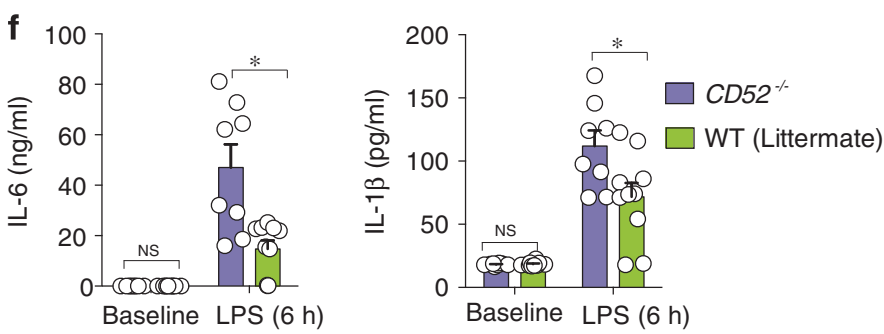
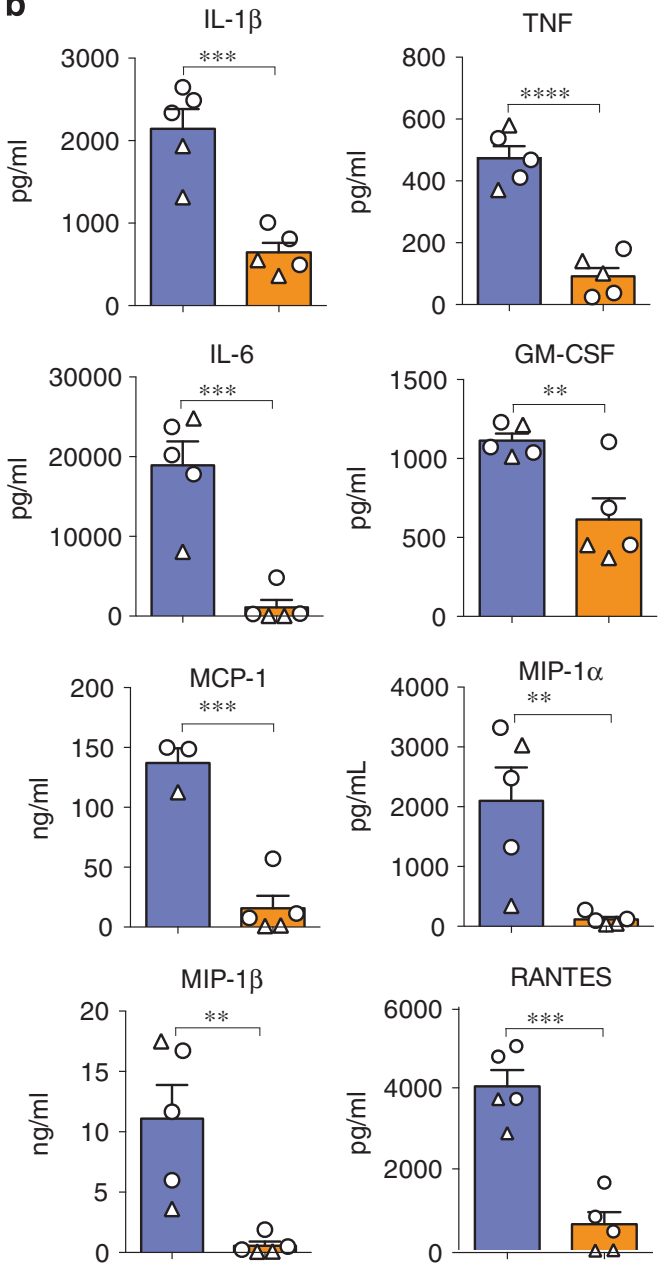

RANTES
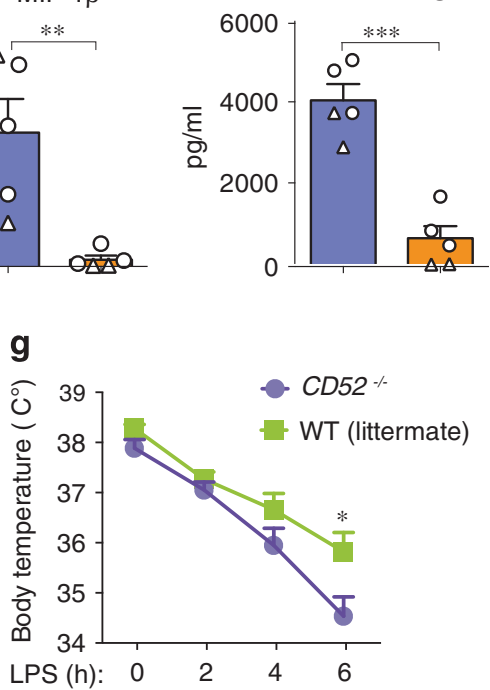

Figure 7 CD52-Fc suppresses LPS-induced inflammation in vivo. (a) C57BL/6 mice were injected with LPS (100 $\mu$ g, i.p.) \pm mCD52-Fc (50 $\mu$ g, i.v.) and plasma TNF levels measured. (b) Plasma cytokines and chemokines were measured $5 \mathrm{~h}$ after C57BL/6 mice were injected with LPS (100 $\mu$ g, i.p.) and either mouse (circle) or human (triangle) $\mathrm{CD} 52-\mathrm{Fc}(50 \mu \mathrm{g}$, i.v.). (c) Body temperature of the mice treated in (a). (d) Clinical features of C57BL/6 mice injected with LPS (100 $\mu \mathrm{g}$, i.p., $5 \mathrm{~h}) \pm \mathrm{mCD} 52-\mathrm{Fc}$ or hCD52-Fc (50 $\mu \mathrm{g}$, i.v.). (e) H\&E-stained sections (top) and scoring of lung tissue pathology (bottom) in mice $5 \mathrm{~h}$ after injection with LPS (100 $\mu$ g, i.p.) \pm mCD52-Fc or hCD520-Fc (50 $\mu \mathrm{g}$ i.v.). (f and g) C57BL/6 mice of the indicated genotypes were injected with LPS (1 mg/kg, i.p.) as indicated and IL-6 and IL-1 $\beta$ concentrations in plasma (f) and body temperature (g) measured. (a-c) mean \pm S.E.M. (a,c) $n=3$ mice per group; (b) $n=5$ mice per group; (f,g) $8-10$ mice per group. ${ }^{\star} P<0.05,{ }^{* \star} P<0.01,{ }^{* \star \star} P<0.001,{ }^{* \star \star *} P<0.0001 ;(\mathbf{a}-\mathbf{c}, \mathbf{f}, \mathbf{g})$ Mann-Whitney test 
Table 1 Criteria for scoring lung injury

\begin{tabular}{lll}
\hline Key & \multicolumn{1}{c}{ Bronchial and vascular } & \\
\hline 0 & No inflammation & Alveolar \\
1 & $\begin{array}{l}\text { Occasional cuffing with inflammatory cells } \\
\text { Most airways/vessels surrounded by a thin layer (1-5 cells } \\
\text { thick) of inflammatory cells }\end{array}$ & $\begin{array}{l}\text { Occasional alveolitis (inflammatory cells in the alveolar spaces) } 1-2 \text { foci } \\
\text { Frequent alveolitis (inflammatory cells in the alveolar spaces) } \geqslant 3 \text { foci }\end{array}$ \\
3 & $\begin{array}{l}\text { Most airways/vessels surrounded by a thick layer ( }>5 \text { cells } \\
\text { thick) of inflammatory cells }\end{array}$ & Occasional/frequent alveolitis with occasional interstitial pneumonia \\
4 & $\begin{array}{l}\text { Not applicable } \\
\text { Not applicable }\end{array}$ & Frequent alveolitis with frequent interstitial pneumonia \\
6 & Not applicable & $\begin{array}{l}\text { Frequent alveolitis and interstitial pneumonia with some loss of alveoli } \\
\text { (emphysema) or activated stroma }\end{array}$ \\
& & $\begin{array}{l}\text { Frequent alveolitis and interstitial pneumonia with frequent loss of alveoli } \\
\text { (emphysema) or activated stroma/fibrosis }\end{array}$ \\
\hline
\end{tabular}

CD52-Fc to efficiently inhibit TLR-mediated NF- $k$ B activation and TNF secretion (Figures $6 \mathrm{~b}$ and $\mathrm{c}$ and Supplementary Figure S4E). Together, these findings demonstrate that inhibition of TLR-induced NF- $k \mathrm{~B}$ and inflammatory cytokine production by CD52-Fc occurs even when cell death is chemically or genetically blocked.

The $\mathbf{N}$-linked glycan moiety is required for the activity of CD52-Fc. The major component of CD52 is its $N$-linked glycan, ${ }^{8}$ and we have previously documented that soluble CD52's $N$-linked glycan is required to inhibit activated T-cell function via interactions with the ITIM-containing lectin receptor, Siglec-10. ${ }^{10}$ Therefore, to assess whether the immunomodulatory effects we observed in macrophages were regulated in the same manner, we cleaved the $\mathrm{N}$-linked glycan from the CD52-Fc peptide using $\mathrm{N}$-glycanase F (PNGase F) (Figure 6d). As predicted, loss of the $N$-linked glycan completely abrogated the ability of CD52-Fc to inhibit LPS-induced NF- $\kappa B$ activation and cause cell death (Figure $6 \mathrm{~d}$ ). Similar to our previous reports in $\mathrm{T}$ cells, ${ }^{10}$ the non-glycosylated CD52 12-mer peptide also had no biological activity on THP-1 cells (Supplementary Figure S5A). However, intriguingly, despite the $N$-linked glycan of CD52 being critical for inhibiting TLR-induced cytokine transcription, neither blocking Siglec-10 with a neutralizing antibody, nor CRISPR gene targeting of Siglec10 in THP-1 cells, diminished the ability of CD52-Fc to prevent TLR-mediated cytokine production (Supplementary Figures S5B-F).

Soluble CD52 suppresses LPS-induced cytokine secretion and features of endotoxic shock in vivo. In view of the fact that CD52-Fc suppressed cytokine responses to LPS in vitro, we tested its therapeutic potential in vivo in a model of endotoxic shock. C57BL/6 mice were injected intraperitoneally with LPS $(100 \mu \mathrm{g}, 5 \mathrm{mg} / \mathrm{kg})$ followed immediately by intravenous injection of mouse or human CD52-Fc $(50 \mu \mathrm{g}$, $2.5 \mathrm{mg} / \mathrm{kg}$ ) or control (PBS or Fc). CD52-Fc suppressed the LPS-induced increase in plasma TNF over time (Figure 7a), as well as a range of other cytokines and chemokines (IL-1 $\beta$, IL-6, GM-CSF, MCP-1, MIP-1 $\alpha$, MIP-1 $\beta$ and RANTES) (Figure 7b). The hypothermic response (Figure 7c) and clinical signs of illness (Figure 7d) after LPS injection were also significantly decreased in mice treated with CD52-Fc. Blinded histological analysis (Table 1) showed that mice treated with CD52-Fc were protected from LPS-induced lung injury (Figure 7e) and macrophage (F4/80+) infiltration (Supplementary Figure S6A).

The ability of CD52-Fc to suppress inflammation in vivo suggested that endogenous CD52 may play a role to dampen innate immune responses. To test this idea, we generated CD52-deficient mice. These mice had no overt phenotype in the first 9 months of life but upon challenge with a low dose of LPS (1 mg/kg i.p.) exhibited significantly increased cytokine (TNF, IL-1 $\beta$, IL-6, MCP-1) and hypothermic responses compared to WT control mice (Figures $7 f$ and $g$, Supplementary Figure S6B and C). Therefore, CD52 acts to inhibit innate immune cell TLR responses both in vitro and in vivo.

\section{Discussion}

In this study we identify soluble CD52 as a novel extracellular negative regulator of PRR signaling, and an inducer of innate immune cell apoptosis. The ability of CD52-Fc to inhibit signaling mediated by different PRR ligands and TNF resulted from its rapid inhibition of NF- $\kappa$ B and ERK, thereby blunting PRR induction of inflammatory cytokines. In addition, a subsequent decrease in short-lived pro-survival genes, such as MCL-1, is likely to result in the apoptotic cell death observed at high doses of CD52-Fc. These mechanistic findings in vitro were recapitulated in vivo, whereby CD52-Fc treatment impaired endotoxin-mediated inflammatory cytokine production and clinical pathology, whereas genetic deletion of CD52 exacerbated responses to LPS. Hence, soluble CD52 represents a physiological anti-inflammatory molecule that may prove beneficial in the treatment of innate immune celldriven inflammatory conditions.

It is important to appreciate, however, that while CD52 is defined simply by a CD (cluster of differentiation) immunophenotype its biological activity is related to its $N$-linked glycan, ${ }^{10}$ which is a complex heterogeneous structure. ${ }^{8}$ Even from the same HEK 293 host cells, we observed batch-tobatch variation in the bioactivity of recombinant CD52-Fc. Furthermore, commercial CD52-Fc had little or no bioactivity in our hands. Variation in the structure of the same glycoform from the same cell is well documented. ${ }^{27}$ Consistent with this, we have found that the biological activity of bulk CD52-Fc is accounted for by a specific glycoform sub-component (unpublished data).

Within minutes, CD52-Fc inhibited the activation of NF- $k \mathrm{~B}$ and ERK by LPS. The $N$-linked glycan was essential for this 
effect, suggesting that CD52-Fc signals through a lectin receptor. Previously, we documented that CD52-Fc binds to Siglec-10 on T cells to inhibit their activation. ${ }^{10}$ However, a neutralizing Siglec-10 antibody or genetic deletion of Siglec10 failed to block CD52-Fc signaling on THP-1 cells, demonstrating that it must signal via different receptors on innate immune cells and $T$ cells. It is plausible that the inhibition of NF- $\kappa \mathrm{B}$ and $\mathrm{ERK}$ signaling by CD52 is mediated by targeting a component common to signaling by multiple TLRs, the IL-1 receptor and TNFR1. Possible downstream CD52 targets therefore include E3 ligases, such as the linear ubiquitin chain complex (e.g. LUBAC) or protein kinases ${ }^{29}$ that have been documented to promote optimal cytokine production following the activation of TLR and TNF receptor family members.

At high concentrations, CD52-Fc induced rapid cell death. The chemical or genetic disruption of killing by CD52-Fc did not prevent CD52-Fc inhibition of TLR-induced NF- $\kappa$ B activation and cytokine secretion, demonstrating that cell death occurs downstream of the inhibition of NF- $\kappa \mathrm{B}$, and that the loss of cellular viability does not account for the anti-inflammatory effects of CD52-Fc. Macrophage and monocyte killing by CD52-Fc was prevented by apoptotic caspase inhibition and was decreased upon deletion of the death receptor initiator caspase, caspase-8. Remarkably, however, death receptor signaling was not required for caspase-8 activation but rather caspase-8 activation occurred downstream of the essential intrinsic apoptotic effector proteins BAX and BAK. This is consistent with evidence that effector caspases such as caspase- 3 can directly process caspase- $8,{ }^{19,20}$ and with the decrease in caspase-8 cleavage and CD52-Fc-induced killing we observed upon BAX and BAK deletion. Considering that CD52-FC-induced caspase activation occurred subsequent to its inhibition of NF- $k B$ and the loss of MCL-1 and $C F L I P_{L}$ these events are likely to be important in triggering cell death. ${ }^{30,31}$ This conclusion is strengthened by the fact that the expression of constitutively active IKK to induce NF- $\kappa \mathrm{B}$ increased both MCL-1 and CFLIP expression and protected from CD52-FCinduced apoptosis, as did the inducible overexpression of MCL-1 alone. The physiological relevance of soluble CD52induced innate immune cell death remains to be explored. However, we suggest that, consequent to suppression of cell function, cell death is the ultimate expression of negative immune regulation, reflecting the strength of CD52 signaling. Our finding with soluble CD52 may be a particular example of a more general mechanism that allows the elimination of hyperstimulated innate immune cells responsible for tissue pathology or that bear pathogens. ${ }^{16}$

In line with our observations in vitro, the systemic administration of CD52-Fc attenuated the production of inflammatory cytokines, and decreased the hypothermic and organ injury responses that characterize the LPS-induced model of endotoxic shock. Conversely, LPS responses were enhanced in CD52 gene-deleted mice. Thus, soluble CD52 acts in vivo to fine-tune PRR induction of inflammatory cytokines and chemokines and is therefore likely to play a role in host immunity to microbial infections. Notably, inflammatory cytokine suppression by soluble CD52 occurred at sub-micromolar concentrations $(10 \mu \mathrm{g} / \mathrm{ml}$ or $165 \mathrm{nM}$ for the human CD52-Fc dimer), which is approximately the same as the local concentration of native CD52 released following T-cell activation. ${ }^{10}$ Thus, soluble CD52 limits innate as well as adaptive immune responses, expanding its therapeutic potential to inflammatory diseases driven by innate immune cells.

\section{Materials and Methods}

Materials. Reagents were as follows: antibodies to $I_{\kappa} \mathrm{B}-\alpha(4812)$ and phospho-

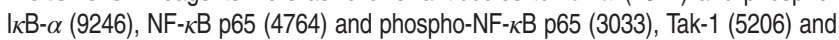
phospho-Tak-1 (4508), p44/42 MAPK (9102) and phospho-P44/42 MAPK (9101), phospho-IKK $\alpha / \beta$ (2697), human caspase-8 (9746), cleaved caspase-8 (mousespecific) (8592), caspase-9 (9508), cleaved caspase 9 (mouse-specific) (9509), PARP (9532), caspase-3 (9662), cleaved caspase-3 (9661), Bak (3814), Bax (2772), MCL-1 (5453), Bcl-xL (2764) and U0126 (9903) (Cell Signaling, Danvers, MA, USA); to cFLIP (NBP1-97663; Novus Biologicals, Littleton, CO, USA); to BCL2 and caspase-8 (WEHI); to CD52 (sc-25838; Santa Cruz Biotechnology, Dallas, TX, USA). All BMDM stimulations were performed with ultrapure LPS (tlr-smlps) and $\mathrm{Pam}_{3} \mathrm{CSK}_{4}$ (ttrl-pms) from InvivoGen (San Diego, CA, USA). Recombinant human TNF (300-01A) and IL-1 $\beta$ (200-01B) were from PeproTech (Rocky Hill, NJ, USA); HMGB1 (HM-101) from HMGBiotech (Milan, Italy); anti-human CD14 microbeads (130-050-201), LS columns (130-042-401) and FCR blocking reagent (130-059-901) from Miltenyi Biotec (Cologne, Germany); APC-Annexin V (550475) and FITCconjugated mouse anti-human CD14 (555397) from BD Biosciences (San Jose, CA, USA); Ficoll/Hypaque from Amersham Pharmacia (Uppsala, Sweden); Q-VD-OPh (03OPH109; MD Biomedicals, Santa Ana, CA, USA) and Nec1s (2263-1) from BioVision (Milpitas, CA, USA); All human monocyte (primary and THP-1 cells) stimulations were performed with LPS (L4391; Sigma-Aldrich, St. Louis MO, USA). Bapta (A1076), APDC (A7361), bafilomycin A1 (B1793), puromycin (P8833) and PD98059 (P215) were also from Sigma-Aldrich; synthetic human CD52 peptide from GL Biochem (Shanghai, China); PNGase F (P0704S) and Factor Xa (P8010S) from New England Biolabs (Ipswich, MA, USA); Strep-Tactin Sepharose from IBA, (Goettingen, Germany); NHS-activated Sepharose 4B from GE Healthcare (Little Chalfont, UK); Mini-EDTA-free protease inhibitor from Roche (Basel, Switzerland); 3,3' diaminobenzidine tetrahydrochloride (DAB) from DAKO (Via Real Carpinteria, CA, USA); PureYield Plasmid Maxiprep System and GoTaq qPCR Master Mix from Promega (Madison, WI, USA); Isolate II RNA mini kit from Bioline (London, UK); SuperScript III First-Strand Synthesis System from Invitrogen (Carlsbad, CA, USA); oligonucleotide primers from Sigma-Aldrich; $\mathrm{pTRH1}$-NF $\kappa$ B-dscGFP plasmid DNA (TR503PA) from System Biosciences (Palo Alto, CA, USA); NuPAGE gels from Invitrogen. Anti-TNF (MAB 610), anti-FasL (MAB126), and anti-TRAIL (MAB375), anti-Siglec-5 (MAB-10721), anti-Siglec-7 (AF-1138), anti-Siglec-9 (MAB-1139), antiSiglec-10(AF-2130), anti-Siglec-11(AF-3258) blocking antibodies, CD52-Fc (9116CD-050) and Siglec-10-Fc (2130-SL) were from (R\&D Systems, Minneapolis, MN, USA). IL- $1 \beta$ was assayed by ELISA (R\&D Systems), TNF and IL-6 by ELISA (eBioscience, San Diego, CA, USA) and other cytokines by multiplex kit (Bio-Rad, Hercules, CA, USA).

Recombinant Fc fusion proteins. As described previously, ${ }^{10}$ PCR was used to generate the signal peptide (SigP) sequence of human CD52 joined to a mutated human IgG1 Fc. ${ }^{11}$ For mouse CD52, the SigP sequence was joined to an Fc PCR-amplified from the NOD mouse IgG2c. The SigP was absent from Fc-only constructs. The constructs included a flexible GGSGG linker, cleavage sites for Factor $\mathrm{Xa}$ (human $\mathrm{CD} 52-\mathrm{Fc}$ ) and PreScission (mouse CD52-Fc) proteases between the SigP and Fc; and at the C-terminus, a Strep-tag II sequence for affinity

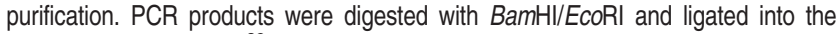
FTGW lentivirus vector. ${ }^{32}$ After sequence verification, plasmids were transformed into competent $E$. coli by heat shock. Competent cells were agitated overnight at $37^{\circ} \mathrm{C}$ in ampicillin broth. Plasmid DNA was purified by PureYield Plasmid Maxiprep System and transiently expressed in HEK $293 \mathrm{~F}$ cells. Recombinant proteins were purified from the medium by single-step affinity chromatography on Streptactin resin and elution with $2.5 \mathrm{mM}$ desthiobiotin in $100 \mathrm{mM}$ Tris- $\mathrm{HCl}, 150 \mathrm{mM} \mathrm{NaCl}, 1 \mathrm{mM}$ EDTA, pH 8.0. Samples were 'polished' by gel filtration chromatography on a Superdex 200 column in PBS under low endotoxin conditions. sodium dodecyl sulfate-polyacrylamide gel electrophoresis (SDS-PAGE) under reducing conditions and Coomassie blue staining revealed a single band of $\sim 48 \mathrm{kDa}$ for the recombinant fusion proteins and $\sim 28 \mathrm{kDa}$ for $\mathrm{Fc}$; specificity was confirmed by immunoblotting. 
The Fc fragment of human CD52-Fc was cleaved with Factor Xa. Factor Xa (5 $\mu \mathrm{g})$ was added to $1 \mathrm{mg} / \mathrm{ml}$ CD52-Fc protein in $500 \mu \mathrm{l}$ of $20 \mathrm{mM}$ Tris-Hcl, $100 \mathrm{mM} \mathrm{NaCl}$, $2 \mathrm{mM} \mathrm{CaCl}_{2}(\mathrm{pH} \mathrm{8.0)}$, and incubated at room temperature for $16 \mathrm{~h}$. The digest was passed sequentially through three Protein G-Sepharose columns (500 $\mu \mathrm{l}$ each) and flow-through containing CD52 collected. After washing, Fc was eluted with glycine$\mathrm{HCl}(\mathrm{pH}$ 2.8) and neutralized by adding $1 \mathrm{M}$ Tris $\mathrm{pH}$ 8.0. Cleavage was confirmed by SDS-PAGE under reducing conditions and immunoblotting, which revealed a single band of $\sim 12 \mathrm{kDa}(\mathrm{CD} 52)$ in the flow-through and $\sim 28 \mathrm{kDa}(\mathrm{Fc})$ in the eluate.

For removal of the CD52-Fc glycan moiety, CD52-Fc $(100 \mu \mathrm{g})$ was incubated with PNGase $\mathrm{F}$ (10 units) or reaction buffer alone, in a volume of $200 \mu$ l overnight at $37^{\circ} \mathrm{C}$. Removal of the $N$-linked oligosaccharide was confirmed by SDS-PAGE under reducing conditions and Coomassie blue staining, which revealed a reduction in the molecular weight of CD52-Fc from $\sim 48$ to $39 \mathrm{kDa}$. The protein solutions were desalted by dialysis against pure sterile water.

Purification of native CD52 from human spleen. Frozen human spleen $(50 \mathrm{~g})$ was cut into small pieces and homogenized with three volumes of water. The homogenate was added with stirring to 11 volumes of methanol and then 5.4 volumes of chloroform were added. After standing for $1 \mathrm{~h}$, two phases formed. The top aqueous phase was collected and evaporated to dryness with a rotatory evaporator, the extract re-suspended, and dialyzed against water for purification. Campath-H1 anti-CD52 humanized rat monoclonal antibody $(1.5 \mathrm{mg})$ was coupled to $1 \mathrm{ml}$ of NHS-activated Sepharose 4B, as per instructions of the manufacturer. The gel was packed into a $10 \mathrm{ml}$ column ( $2 \mathrm{ml}$ bed volume) and washed three times with PBS containing $50 \mathrm{mM}$ diethylamine (pH 11.5). The spleen extract was recycled three times through the column. After washing 100 column volumes of PBS, the column was eluted with 5 volumes of a solution of $50 \mathrm{mM}$ diethylamine, $500 \mathrm{mM}$ $\mathrm{NaCl}$ containing $0.5 \%$ sodium deoxycholate, $\mathrm{pH} 11.5$, and neutralized with $1 \mathrm{M}$ Tris$\mathrm{HCl}(\mathrm{pH}$ 8.0). Fractions containing CD52 were identified by immunoblotting, pooled, dialyzed against water, freeze-dried and re-suspended in PBS.

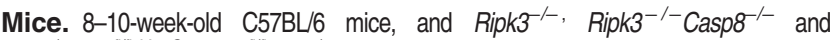

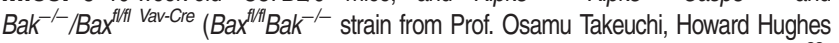
Medical Institute, Dana-Farber Cancer Institute, Harvard Medical Schoo ${ }^{33}$ ) mice generated on, or backcrossed onto (>10 generations), a C57BL/6 background were bred at the Walter and Eliza Hall Institute. Their experimental use was approved by the Institute's Animal Ethics Committee. C57BL/6 mice in which targeted homologous recombination was used to create lox-p sites flanking exon 2 of CD52 $\left(C D 52^{f / f / T}\right)$ were generated by Ozgene Pty Ltd, Australia. The neomycin resistance cassette was removed by breeding with the FLPe deleter strain. Whole body knockout of CD52 was achieved by breeding CD52 $2^{\mathrm{fl} / \mathrm{fl}}$ mice with heterozygous transgenic CMV promoter-Cre mice on the C57BL/6 background (obtained from Ursula Lichtenberg, Institute for Genetics, University of Cologne). Mice were bred to remove the transgene, selecting for homozygous CD52 deleted mice that were then interbred. Homozygosity was confirmed by PCR of tail DNA with primers flanking the loxP insertion sites, giving an expected product of $\approx 225 \mathrm{bp}$ compared to the wild-type product of $\approx 769 \mathrm{bp}$. Primers were: $5^{\prime}$-ccacattgggtttctgttc-3'; 5'-atgaagacatcaagggcatgg-3'.

Human tissues. Buffy coats from healthy human volunteers were from the Australian Red Cross. Peripheral blood mononuclear cells (PBMCs) were isolated on a Ficoll/Hypaque density gradient. Cell viability was routinely $95 \%$. CD $14^{+}$cells from PBMCs were enriched with microbeads conjugated to monoclonal anti-human CD14 antibody using MACS magnetic LS columns. The purity of CD14 ${ }^{+}$monocytes exceeded $90 \%$, as determined by flow cytometry. Organ donor spleen tissue was obtained through the Australian Islet Transplant Consortium. Studies with human tissues were approved by the Human Research Ethics Committees of Melbourne Health and St. Vincent's Hospital, Melbourne.

Cells. The human monocyte cell line THP-1 was maintained in RPMI, $10 \%$ fetal bovine serum (FBS) and $10 \mathrm{mg} / \mathrm{ml}$ penicillin/streptomycin (pen/strep) at $37^{\circ} \mathrm{C}$ in $5 \%$ $\mathrm{CO}_{2} /$ air. BMDMs were generated from bone marrow extracted from tibiae and femora of C57BL/6 mice and cultured in DME medium containing 10\% FBS, $20 \%$ L929 conditioned medium at $37{ }^{\circ} \mathrm{C}$ in $10 \% \mathrm{CO}_{2}$; after 7 days, adherent cells were harvested and used for experiments.

Generation of NF-кB reporter THP-1 cells. THP-1 cells were transduced with lentivirus particles packaged with an expression vector encoding the dscopGFP reporter gene driven by the cytomegalovirus (mCMV) promoter in conjunction with four copies of the NF- $\kappa \mathrm{B}$ consensus transcriptional response element upstream of mCMV (pTRH1-NF $\kappa$ B-dscGFP; System Biosciences). Lentivirus particles were produced by $\mathrm{CaPO}_{4}$-mediated transfection of HEK293T cells $\left(4 \times 10^{6}\right)$ seeded in $6 \mathrm{~cm}$ dishes with $10 \mu \mathrm{g}$ of vector DNA together with three helper plasmids (pMDLRRE, pRSV-REV and pVSV-g). Virus-containing cell culture medium was collected $48 \mathrm{~h}$ after transfection and passed through a $0.45 \mu \mathrm{m}$ filter. THP-1 cells were infected by virus-containing medium in presence of $8 \mu \mathrm{g} / \mathrm{ml}$ protamine sulfate by centrifugation for $3 \mathrm{~h}$ at $32^{\circ} \mathrm{C}$. Cells were screened for GFP expression by flow cytometry.

Generation of constitutively active NF-кB THP-1 cells. A lentiviral $4 \mathrm{HT}$-inducible cDNA vector system ${ }^{23}$ was used to inducibly express constitutively active IKK2-EE. ${ }^{24}$ To generate lentiviral particles, HEK293T cells were transfected using lipofectamine. After $48 \mathrm{~h}$, the virus-containing supernatants were harvested and filtered through a $0.45 \mu \mathrm{m}$ syringe filter. NF- $\kappa B$ reporter THP-1 cells were infected with virus supernatant in presence of $8 \mu \mathrm{g} / \mathrm{ml}$ polybrene by centrifugation for $3 \mathrm{~h}$ at $32{ }^{\circ} \mathrm{C}$. To induce NF- $\kappa$ B activation, cells were treated with $10 \mathrm{nM} \mathrm{4-}$ hydroxytamoxifen for $16 \mathrm{~h}$.

Generation of inducible cFLIPL and MCL-1 THP-1 cells. Lentiviral $4 \mathrm{HT}$-inducible ${ }^{23}$ and doxycycline-inducible ${ }^{34}$ vectors were used to express MCL-1 and CFLIP , respectively. To induce MCL-1 and CFLIP, cells were treated for $16 \mathrm{~h}$ with $10 \mathrm{nM}$ of 4-hydroxytamoxifen and $1 \mu \mathrm{g} / \mathrm{ml}$ of doxycycline, respectively.

Generation of Siglec-10-deficient THP-1 cells. CRISPR/Cas9 targeting of Siglec-10 in THP-1 cells was performed as previously described. ${ }^{35}$ The sgRNAs were designed by MIT CRISPR software (http://crispr.mit.edu). Three sgRNA sequences $5^{\prime}$-gagattctggatacgagtgc-3', 5'-ctaccccagcttatggctac-3' and 5'cacaaaccaccagagtcgag- $3^{\prime}$ in the second exon of Siglec-10 were ligated into the $\mathrm{BsmB} 1$ restriction site of the lentiviral doxycycline inducible sgRNA vector ( $\mathrm{FgH} 1 \mathrm{t}-$ UTG, harboring constitutively expressed eGFP). ${ }^{35}$ Cas9 (marked by mCherry expression) containing THP-1 cells were infected with sgRNA constructs and sorted for mCherry (Cas9) and eGFP (sgRNA) expression, as previously described. ${ }^{35,36} \mathrm{To}$ induce the expression of sgRNAs, THP-1 cells were treated with doxycycline $(1 \mu \mathrm{g} /$ $\mathrm{ml})$. The InDel mutation of Siglec-10 was confirmed by next generation sequencing ${ }^{35}$ and quantitative RT-PCR.

Annexin V and PI staining. Cells were incubated with Annexin $V$ conjugated to APC in $1 \mathrm{X}$ binding buffer containing $10 \mathrm{mM}$ HEPES (pH 7.4), $140 \mathrm{mM} \mathrm{NaCl}$, and $2.5 \mathrm{mM} \mathrm{CaCl} 2$ for $15 \mathrm{~min}$ at room temperature. Immediately prior to flow cytometric analysis, $1 \mu \mathrm{g} / \mathrm{ml} \mathrm{PI}$ was added.

In vitro studies. THP-1 cells, NF- $\kappa$ B reporter THP-1 cells, primary human monocytes, fetal liver-derived macrophages, BMDMs were cultured in triplicate in 96-well plates at a density of $2 \times 10^{5}$ cells/well or in 24-well plates at a density of $4 \times 10^{5} \mathrm{cells} /$ well, in $400 \mu \mathrm{l}$ of medium. Cells were exposed to CD52-Fc or Fc control with or without pre-incubation with different inhibitors or stimuli for different time points, as described in the figure legends. Human and mouse IL-1 $\beta$ (R\&D Systems), human and mouse TNF and other cytokines were measured in media by ELISA (eBioscience) or Bioplex bead array (Bio-Rad). NF- $\kappa B$ reporter THP- 1 cells were washed and the MFI of GFP was detected using a FACSVerse flow cytometer (BD Biosciences).

Quantitative PCR. THP-1 cells were untreated or exposed to carrier, CD52-Fc or Fc control $(20 \mu \mathrm{g} / \mathrm{ml})$ in the presence of LPS $(100 \mathrm{ng} / \mathrm{ml})$. After 1,2 and $4 \mathrm{~h}$ cells were harvested, washed with PBS and total RNA extracted (Isolate II RNA mini kit from Bioline). CDNA was synthesized from $1 \mu \mathrm{g}$ of total RNA using random hexamers and Super Script Reverse Transcriptase III. GoTaq qPCR Master Mix $(7.5 \mu l)$ was added to $7.5 \mu \mathrm{l}$ containing CDNA $(1 \mu \mathrm{l})$ and gene-specific forward and reverse primers $(5 \mu \mathrm{M})$. CDNA was amplified for 50 cycles in a Viia7 real-time PCR machine. The expression of mRNA was normalized to endogenous $\beta$-actin expression. The primers were: human TNF forward, $5^{\prime}$-tccttcagacaccctcaacc- $3^{\prime}$ and reverse, $5^{\prime}$-aggccccagtttgaattctt-3'; human IL-6 forward, $5^{\prime}$-caatgaggagacttgcctggtg and reverse, 5'-gttgggtcaggggtggttattg-3'; human IL-1 $\beta$ forward, $5^{\prime}$-ctgtcctgc gtgttgaaaga- $3^{\prime}$ and reverse, $5^{\prime}$-ttctgcttgagaggtgctga- $3^{\prime}$, human actin forward, $5^{\prime}$ agagctacgagctgcctgac-3' and reverse, $5^{\prime}$-agcactgtgttggcgtacag- $3^{\prime}$, human Siglec-10 forward $5^{\prime}$-gcatcacggctcttctttc- $3^{\prime}$ and reverse $5^{\prime}$-gtccgaggactgtttggtgt- $3^{\prime}$. 
Immunoblotting. Cell lysates were fractionated by SDS-PAGE (4-12\%). Proteins were then electrophoretically transferred to nitrocellulose membranes and blocked overnight in 5\% w/v skim milk in Tris-buffered saline and $1 \%$ Tween (TBST) prior to incubation with primary antibody. Primary antibody incubations in $5 \% \mathrm{w} / \mathrm{v}$ skim milk TBST were performed overnight at $4{ }^{\circ} \mathrm{C}$ and secondary antibody incubations $(5 \% \mathrm{w} / \mathrm{V}$ skim milk, TBST) were for $1-2 \mathrm{~h}$ at room temperature. Membranes were washed 3-5 times in TBST and proteins detected by enhanced chemiluminescence imaging (Amersham Biosciences, Parramatta, NSW, Australia).

Immunohistochemistry. Tissues were fixed in buffered formalin (10\%). Tissue sections were de-paraffinized and antigen retrieval was performed with trypsin buffer. Sections were incubated with $3 \%$ hydrogen peroxide (v/v) for $15 \mathrm{~min}$ to block endogenous peroxidase activity and then incubated for 45 min with $10 \%$ normal goat serum to block non-specific binding of immunoglobulin. Staining was performed with rat anti-mouse $\mathrm{F} 4 / 80$ antibody $(2 \mu \mathrm{g} / \mathrm{ml})$, incubated overnight at $4^{\circ} \mathrm{C}$, followed by secondary antibody (biotinylated goat anti-rat lgG antibody) ( $1: 200$ dilution) for $45 \mathrm{~min}$ and HRP-avidin-biotinylated complex (HRP-ABC) for $30 \mathrm{~min}$ at RT (antibodies were diluted in $10 \%$ normal goat serum). Sections were washed $5 x$ in mouse tonicity-PBS after antibody incubations and immunoperoxidase staining was detected with the DAB.

In vivo studies. Female C57BL/6 mice aged 10 weeks were injected with LPS (100 $\mu$ g i.p.) followed immediately by mCD52-Fc, or hCD52-Fc or hFc (50 $\mu$ g, i.v.). For measurement of plasma cytokines, blood was sampled from the retroorbital venous plexus at baseline, 2 and $4 \mathrm{~h}$ and by heart bleed at $5 \mathrm{~h}$ (following $\mathrm{CO}_{2}$-induced asphyxia). After $5 \mathrm{~h}$, lung, liver and kidney were removed for fixation and staining by hematoxylin and eosin. Tissue sections were scored in a blinded manner. A scoring system (Table 1) was devised to evaluate the lung injury. Scoring of the airways and vasculature was based on the criteria of Choi et al..$^{37}$ and Curtis et al., ${ }^{38}$ and for the alveoli of Ashcroft et al. ${ }^{39}$ and Chang et al. ${ }^{40}$ Female CD52 knockout mice and wild-type littermates or C57BL/6 mice (age- and sex-matched) were injected with LPS (1 mg/kg i.p.). Blood was sampled from the retro-orbital venous plexus at baseline and $6 \mathrm{~h}$ and at $10 \mathrm{~h}$ by heart bleed (following $\mathrm{CO}_{2^{-}}$ induced asphyxia) for measurement of plasma cytokines.

Statistics. Differences between two groups were analyzed by Mann-Whitney test and between two groups or more analyzed by Kruskal-Wallis test, using Prism software (GraphPad Software, Version 6).

\section{Conflict of Interest}

The authors declare no conflict of interest.

Acknowledgements. We thank G. Naselli, K. Ngui, J. Bosco, N. Stone, R Boehmer, N. Khan, L. Dagley, P. Nguyen for technical assistance and advice. We thank I. Wicks, J. Murphy, H. Thomas, S.L. Masters, A. Webb, R. Feltham, E. Petrie, S. Nicholson for insightful discussions. We thank L. Schofield for providing THP-1 cells, N. Lalaoui, D. Vaux and J. Silke for the ERK inhibitors and PARP antibody, NF$\kappa \mathrm{B}$ reporter, GEV-16 and MCL-1 CDNA constructs. G. Salvesen and M. Navarro for the inducible $c F L I P_{L} c D N A$ construct, P. Meier for the IKK-EE mutant construct and $D$. Huang, K. Mason and D. Gray for BAX/BAK double knockout mice, O. Takeuchi for the $\mathrm{Bax}^{\mathrm{fl} / \mathrm{fl}} \mathrm{Bak}^{-/-}$strain and J. Gillbert, M. Dayton, D. Cooper for technical assistance. This work was supported by the National Health and Medical Research Council of Australia Program Grant (LCH 1037321), Project Grants (LCH 1051484; JEV 1051210 and 1101405). Fellowships (LCH 1080887; JEV 1052598), and by operational infrastructure grants through the Australian Government IRISS (9000220) and the Victorian State Government OIS.

\section{Author contributions}

$\mathrm{LCH}, \mathrm{JEV}$ and MR designed the study. MR performed the experiments and analyzed the data with LCH and JEV. EB-S, KEL,YZ, SLV, RO, TEA and JMW performed experiments and provided expert advice. $\mathrm{LCH}$ and AMN generated CD52-deficient mice. MR, JEV and LCH wrote the manuscript. All authors discussed and commented on the manuscript.

1. Takeuchi O, Akira S. Pattern recognition receptors and inflammation. Cell 2010; 140: 805-820.

2. Akira S, Uematsu S, Takeuchi O. Pathogen recognition and innate immunity. Cell 2006; 124: 783-801.
3. Chen GY, Nuñez G. Sterile inflammation: sensing and reacting to damage. Nat Rev Immunol 2010; 10: 826-837.

4. Savva A, Roger T. Targeting toll-like receptors: promising therapeutic strategies for the management of sepsis-associated pathology and infectious diseases. Front Immunol 2010; 4: $1-16$.

5. Hong-Geller E, Chaudhary A, Lauer S. Targeting toll-like receptor signaling pathways for design of novel immune therapeutics. Curr Drug Discov Technol 2008; 5: 29-38.

6. Hale G. CD52 (CAMPATH1). J Biol Regul Homeost Agents 2001; 15: 386-391.

7. Xia MQ, Tone M, Packman L, Hale G, Waldmann H. Characterization of the CAMPATH-1 (CDw52) antigen: biochemical analysis and CDNA cloning reveal an unusually small peptide backbone. Eur J Immunol 1991; 21: 1677-1684.

8. Treumann A, Lifely MR, Schneider P, Ferguson MA. Primary structure of CD52. J Biol Chem 1995; 270: 6088-6099.

9. Rao SP, Sancho J, Campos-Rivera J, Boutin PM, Severy PB, Weeden T et al. Human peripheral blood mononuclear cells exhibit heterogeneous CD52 expression levels and show differential sensitivity to alemtuzumab mediated cytolysis. PloS One 2012; 7: e39416.

10. Bandala-Sanchez E, Zhang Y, Reinwald S, Dromey JA, Lee BH, Qian J et al. T cell regulation mediated by interaction of soluble CD52 with the inhibitory receptor Siglec-10. Nat Immunol 2013; 14: 741-748.

11. Armour KL, van de Winkel JG, Williamson LM, Clark MR. Differential binding to human FcyRlla and FcyRllb receptors by human IgG wildtype and mutant antibodies. Mol Immunol 2003; 40: 585-593.

12. Tone M, Nolan KF, Walsh LA, Tone $Y$, Thompson SA, Waldmann H. Structure and chromosomal location of mouse and human CD52 genes. Biochim Biophys Acta 1999; 1446: 334-340.

13. Vince JE, Pantaki D, Feltham R, Mace PD, Cordier SM, Schmukle AC et al. TRAF2 must bind to cellular inhibitors of apoptosis for tumor necrosis factor (TNF) to efficiently activate NF-kB and to prevent TNF-induced apoptosis. J Biol Chem 2009; 284: 35906-35915.

14. Hotokezaka H, Sakai E, Kanaoka K, Saito K, Matsuo K, Kitaura H et al. U0126 and PD98059, specific inhibitors of MEK, accelerate differentiation of RAW264.7 cells into osteoclastlike cells. J Biol Chem 2002; 277: 47366-47372.

15. Kearney CJ, Cullen SP, Tynan GA, Henry CM, Clancy D, Lavelle EC et al. Necroptosis suppresses inflammation via termination of TNF-or LPS-induced cytokine and chemokine production. Cell Death Differ 2015; 22: 1313-1327.

16. Speir M, Lawlor KE, Glaser SP, Abraham G, Chow S, Vogrin A et al. Eliminating legionella by inhibiting BCL-XL to induce macrophage apoptosis. Nat Microbiol 2016; 1: 15034.

17. Goodall KJ, Finch-Edmondson ML, van Vuuren J, Yeoh GC, Gentle IE, Vince JE et al. Cycloheximide can induce Bax/Bak dependent myeloid cell death independently of multiple BH3-only proteins. PLOS One 2016; 11: e0164003.

18. Delbridge A, Strasser A. The BCL-2 protein family, BH3-mimetics and cancer therapy. Cell Death Differ 2015; 22: 1071-1080.

19. Ferreira KS, Kreutz C, Macnelly S, Neubert K, Haber A, Bogyo M et al. Caspase-3 feeds back on caspase-8, Bid and XIAP in type I Fas signaling in primary mouse hepatocytes. Apoptosis 2012; 17: 503-515.

20. Tang D, Lahti JM, Kidd VJ. Caspase-8 activation and BID cleavage contribute to MCF7 cellular execution in a caspase-3-dependent manner during staurosporine-mediated apoptosis. J Biol Chem 2000; 275: 9303-9307.

21. Micheau O, Lens S, Gaide O, Alevizopoulos K, Tschopp J. NF-kB signals induce the expression of c-FLIP. Mol Cell Biol 2001; 21: 5299-5305.

22. Liu H, Yang J, Yuan Y, Xia Z, Chen M, Xie L et al. Regulation of Mcl-1 by constitutive activation of NF-kappaB contributes to cell viability in human esophageal squamous cell carcinoma cells. BMC Cancer 2014; 14: 98.

23. Callus BA, Ekert PG, Heraud JE, Jabbour AM, Kotevski A, Vince JE et al. Cytoplasmic p53 is not required for PUMA-induced apoptosis. Cell Death Differ 2008; 15: 213-215.

24. Mercurio F, Zhu H, Murray BW, Shevchenko A, Bennett BL, Li J et al. IKK-1 and IKK-2: cytokine-activated IКB kinases essential for NF-КB activation. Science 1997; 278: 860-866.

25. Chang DW, Xing Z, Pan Y, Algeciras-Schimnich A, Barnhart BC, Yaish-Ohad S et al. c-FLIPL is a dual function regulator for caspase-8 activation and CD95-mediated apoptosis. EMBO J 2002; 21: 3704-3714.

26. Hughes MA. Co-operative and hierarchical binding of C-FLIP and caspase 8: a unified model defines how c-FLIP isoforms differentially control cell fate. Mol Cell 2016; 61: 834-849.

27. Hua S, Nwosu CC, Strum JS, Seipert RR, An HJ, Zivkovic AM et al. Site-specific protein glycosylation analysis with glycan isomer differentiation. Anal Bioanal Chem 2012; 403: 1291-1302.

28. Page TH, Smolinska M, Gillespie J, Urbaniak AM, Foxwell BM. Tyrosine kinases and inflammatory signalling. Curr Mol Med 2009; 9: 69-85.

29. Moulding DA, Giles RV, Spiller DG, White MR, Tidd DM, Edwards SW. Apoptosis is rapidly triggered by antisense depletion of MCL-1 in differentiating U937 cells. Blood 2000; 96: 1756-1763.

30. He M-X, He Y-W. C-FLIP protects T lymphocytes from apoptosis in the intrinsic pathway. $J$ Immunol 2015; 194: 3444-3451. 
31. Herold MJ, van den Brandt J, Seibler J, Reichardt HM. Inducible and reversible gene silencing by stable integration of an shRNA-encoding lentivirus in transgenic rats. Proc Natl Acad Sci USA 2008; 105: 18507-18512.

32. Takeuchi O, Fisher J, Suh H, Harada H, Malynn BA, Korsmeyer SJ. Essential role of BAX, BAK in B cell homeostasis and prevention of autoimmune disease. Proc Natl Acad Sci USA 2005; 102: 11272-11277.

33. Murphy JM, Czabotar PE, Hildebrand JM, Lucet IS, Zhang JG, Alvarez-Diaz S et al. The pseudokinase MLKL mediates necroptosis via a molecular switch mechanism. Immunity 2013; 39: 443-453.

34. Aubrey BJ, Kelly GL, Kueh AJ, Brennan MS, O'Connor L, Milla L et al. An inducible lentiviral guide RNA platform enables the identification of tumoressential genes and tumor-promoting mutations in vivo. Cell Rep 2015; 10: 1422-1432.
35. Baker PJ, Boucher D, Bierschenk D, Tebartz C, Whitney PG, D'Silva DB et al. NLRP3 inflammasome activation downstream of cytoplasmic LPS recognition by both caspase-4 and caspase-5. Eur J Immunol 2015; 45: 2918-2926.

36. Choi YH, Jin GY, Chang L, Yan GH. Inhibition of protein kinase $\mathrm{C}$ delta attenuates allergic airway inflammation through suppression of PI3K/Akt/mTOR/HIF-1 alpha/VEGF pathway. PloS One 2013; 8: e81773.

37. Curtis J, Byrd $\mathrm{P}$, Warnock M, Kaltreider $\mathrm{H}$. Requirement of $\mathrm{CD} 4$ positive $\mathrm{T}$ cells for cellular recruitment to the lungs of mice in response to a particulate intratracheal antigen. J Clin Invest 1991; 88: 1244-1254.

38. Ashcroft T, Simpson JM, Timbrell V. Simple method of estimating severity of pulmonary fibrosis on a numerical scale. J Clin Pathol 1988; 41: 467-470.

39. Chang W, Chang W, Wei K, Ho L, Berry GJ, Jacobs SS et al. A critical role for the mTORC2 pathway in lung fibrosis. PLoS One 2014; 9: e106155.

Supplementary Information accompanies this paper on Cell Death and Differentiation website (http://www.nature.com/cdd) 